\title{
Functional maps of neocortical local circuitry
}

\author{
Alex M. Thomson* and Christophe Lamy \\ The Department of Pharmacology, The School of Pharmacy, University of London, London, UK \\ Review Editors: Gilad Silberberg, Nobel Institute for Neurophysiology, Karolinska Institute, Sweden \\ Ora Ohana, Department of Biology-Chemistry-Pharmacy, Freie Universität Berlin, Germany
}

\begin{abstract}
This review aims to summarize data obtained with different techniques to provide a functional map of the local circuit connections made by neocortical neurones, a reference for those interested in cortical circuitry and the numerical information required by those wishing to model the circuit. A brief description of the main techniques used to study circuitry is followed by outline descriptions of the major classes of neocortical excitatory and inhibitory neurones and the connections that each layer makes with other cortical and subcortical regions. Maps summarizing the projection patterns of each class of neurone within the local circuit and tables of the properties of these local circuit connections are provided.

This review relies primarily on anatomical studies that have identified the classes of neurones and their local and long distance connections and on paired intracellular and whole-cell recordings which have documented the properties of the connections between them. A large number of different types of synaptic connections have been described, but for some there are only a few published examples and for others the details that can only be obtained with paired recordings and dye-filling are lacking. A further complication is provided by the range of species, technical approaches and age groups used in these studies. Wherever possible the range of available data are summarised and compared. To fill some of the more obvious gaps for the less well-documented cases, data obtained with other methods are also summarized.
\end{abstract}

Keywords: cortex, pyramidal cell, interneuron(e), synapse, EPSP/C (excitatory postsynaptic potential/current), IPSP/C (inhibitory postsynaptic potential/current)

\section{INTRODUCTION}

To provide important details such as the probability of a given type of connection occurring, the amplitude of the resultant postsynaptic potential, its time course and dynamic properties, this review relies heavily on data obtained from paired intracellular and paired whole-cell recordings. However, not all of the possible connection types that may exist in neocortex have yet been explored in this way. In some cases, other methods indicate their existence, their prevalence, and provide information about their properties and where relevant these will also be cited.

The different methodologies that have been employed to study local circuitry will be summarized first; not in terms of precise experimental details, but in terms of the form that the resultant information takes. This includes a discussion of the extent to which data obtained with one method can be extrapolated to provide comparisons with those obtained with another method and the extent to which data obtained using different approaches can be combined to generate maps of functional circuitry.

* Correspondence: Alex M. Thomson. The Department of Pharmacology, The School of Pharmacy, University of London, 29-39 Brunswick Square, London WC1N 1AX, UK.e-mail: alex.thomson@pharmacy.ac.uk

Abbreviations: AP, action potential; AHP, after hyperpolariz ation; CC, cortico-cortical CT, Cortico-thalamic; EPSP/C, excitatory postsynaptic potential/current; FS, fast spiking; IPSP/C, inhibitory postsynaptic potential/current; LTS, low threshold spiking; nRT, nucleus reticularis thalami.

Received: 15 August 2007; paper pending published: 01 September 2007; accepted: 01 September 2007; published online: 15 October 2007.

Full citation: Frontiers in Neuroscience. (2007) vol. 1, iss. 1,19-42.

Copyright: (C) 2007 Thomson and Lamy. This is an open-access article subject to an exclusive license agreement between the authors and the Frontiers Research Foundation, which permits unrestricted use, distribution, and reproduction in any medium, provided the original authors and source are credited.
Some recently developed techniques that have not, as yet, provided large quantities of data relevant to this review, but which may be invaluable tools in the future are also outlined.

The classes of well-characterized neocortical neurones that have been included in this review are then summarized and within the sections describing pyramidal cells, the major inputs and outputs associated with each layer are outlined. The reader is referred to citations associated with tables and diagrams for methodological details. Wherever possible, all available information has been reviewed by the authors. Where detailed information relating to synaptic properties is provided by paired recordings with parallel anatomy, these will be given preference. Where paired recording data are too sparse, or absent, the review relies upon other studies such as those using caged glutamate, or those that employ primarily anatomical techniques.

\section{THE TECHNIQUES THAT HAVE BEEN EMPLOYED TO STUDY LOCAL CIRCUIT CONNECTIONS}

The major technical approaches used to provide circuit data, are introduced here in brief.

\section{Anatomical studies}

In addition to providing us with the structural and immunocytochemical details that allow different classes of neocortical neurones to be defined, these studies demonstrate the layer(s) in which each type of neurone receives its inputs and the layer(s), cortical regions and/or subcortical structures to which each type projects. In some ultrastructural studies, it has been possible to identify both the presynaptic and the postsynaptic neurones involved in particular classes of connection. However, this 
requires markers, identifiable at the EM level that unambiguously identify the presynaptic and the postsynaptic elements. This has been achieved in some cases by combining Golgi, or HRP staining of one cell and immunocytochemical labeling of a population of potential targets. Some studies have relied on recognition of postsynaptic subcellular elements such as somata, axon initial segments, and dendritic spines at the ultrastructural level. In others, retrograde labeling of a population of axons and thus their parent neurones has been combined with lesions to promote degeneration of axons and terminals in the recipient region studied. Both the filled neurones and the degenerating terminals can then be identified at the EM level.

The subcellular compartment(s) of pyramidal cells innervated by the axons of a given class, particularly those of presynaptic interneurones, have been defined by ultrastructural studies of the terminals of axons labeled, e.g., by the Golgi technique, by HRP- or biocytin-filling. In this way, the specific postsynaptic subcellular targets of specific interneurone classes, such as chandelier cells, basket cells, and dendrite-preferring Martinotti and double bouquet cells have been identified. However, where the target is a postsynaptic pyramidal dendrite, often definable only by the presence of spines and the dendritic shaft diameter, it can be difficult to determine in which layer the soma of that spiny cell lies, or indeed, what type of pyramidal cell or spiny stellate cell the dendrite belongs to. Moreover, these detailed ultrastructural studies are not available for the majority of classes of local excitatory connection.

For estimates of the densities of each cell class in each layer, of dendritic lengths and of the numbers of boutons supplied, by each cell class in each layer, readers are referred to an excellent analysis of anatomical data by Binzegger et al. (2004). In that study of cat primary visual cortex (V1), 39 neocortical neurones of different types plus the thalamo-cortical axons of $X$ and $Y$ lateral geniculate nucleus (LGN) relay cells were filled with HRP in vivo and were reconstructed. From these reconstructions, they calculated the length of dendrite from each cell type that would be available to receive synaptic connections in each layer and counted the numbers of symmetric (inhibitory) or asymmetric (excitatory) synapses that would be generated by the axon of each type of neurone in each layer. The estimates of total synapse numbers were then compared with estimates based on stereological analysis (Beaulieu and Colonnier, 1985). For layers $2 / 3$ and 5 , the estimates of asymmetric synapses obtained with the two approaches were very close (within 10\%). For layer 4, however, there was a discrepancy of $32 \%$ and for layer 6 a discrepancy of $70 \%$, indicating that additional excitatory inputs, e.g., from subcortical structures such as the claustrum or from other cortical regions, provide a significant number of boutons in these layers. To obtain estimates of the frequency with which one class of neocortical neurone will innervate each class of potential postsynaptic neurone in each layer, they made the basic assumption that there is no selectivity in the connections made. Predictions of "hit rates" were based on the number of boutons from a given class of potential presynaptic cell in a given layer and the proportion of the available targets (e.g., dendritic length) in that layer belonging to another class. This study has provided the basis for a number of circuit models. It also allows the selectivity that appears, from the results of paired recordings, to govern the formation of cortical synapses to be compared with what could be expected in an anatomically accurate random connectivity model.

Larger-scale information about projection patterns between layers and across columns has been obtained from populations of neurones labeled by uptake of dye from an extracellular injection in vivo, providing the basis for many predictions of connectivity patterns. However, only a few of these studies have identified the specific cellular and subcellular targets of these projections beyond, for example, the proportions that involve dendritic spines or shafts. In the future, techniques such as those described by Wickersham et al. (2007) for use in organotypic slice cultures may become applicable to more mature in vivo and ex vivo preparations. This technique uses a trans-synaptic tracer based on rabies virus that can label multiple presynaptic neurones from the transfection of a single postsynaptic neurone.

\section{Immunofluorescence, single cell RT-PCR for identification of cellular markers and 'green mice'}

In brief, when a cell has been labeled with biocytin the biocytin can be visualized in two ways, both dependent upon the exceptionally high affinity with which the protein avidin binds to biotin (biocytin is a conjugate of biotin and lysine). A method increasingly employed is to use avidin tagged with a fluorescent probe and to label specific cellular markers such as the calcium-binding proteins parvalbumin, calbindin, or calretinin with a specific antibody to which a fluorescently labeled secondary antibody is then attached. Using fluorescent probes with different excitation and emission wave lengths, it is relatively straightforward to visualize two specific markers and the biocytin simultaneously (Hughes et al., 2000). If information about multiple markers is required, more complex processing procedures involving wash out or bleaching of the original labels may be necessary. Permanent staining of the biocytin to reveal the dendritic and axonal arbours can then be performed and the cell(s) reconstructed.

An alternative to immunofluorescence, successfully followed by only a few laboratories, is single cell RT-PCR (reverse transcription followed by the polymerase chain reaction, e.g., Porter et al., 1998; Toledo-Rodriguez et al., 2005). Very simplistically, this requires the cytoplasm of a single cell to be harvested with the patch pipette. cDNA is reverse transcribed from the mRNA in the sample, amplified and identified with specific oligonucleotide probes. A larger number of markers can be identified with this approach and it has been used very effectively to demonstrate the relative correlations between the gross morphology, firing characteristics, synaptic properties, and neurochemistry of neocortical neurones. Perhaps the most common criticism of this approach and of the use of in situ hybridization is that mRNA rather than protein is identified. However, in general the results obtained correlate well with those obtained with other methods and provide important insight into the relationship between genotype and phenotype and which proteins are most strongly correlated with the expression of a given characteristic.

An increasingly utilized approach is the use of genetically modified mice in which the expression of green fluorescent protein (GFP) is linked to the promoter for a selectively expressed protein such as GAD-67 (Yuste, 2005 , for review). Following careful comparison of the expression of markers in the GFP-labeled neurones with markers in unlabeled cells, it has been possible to identify a number of mouse lines that express GFP only in certain subpopulations of interneurones (see also section on somatostatincontaining interneurones). The cells expressing GFP can be visualized in the slice and recordings targeted specifically to certain subclasses of neurones. Apart from the need, common to most transgenic studies, to use mice rather than the previously better documented rat, the common criticism of this approach is the potential for damage to the neurones when the GFP is excited.

\section{Focal flash photolysis of caged glutamate}

This approach employs an intracellular/whole-cell recording from one neurone in an in vitro slice while many different regions of that slice are activated sequentially by uncaging glutamate (e.g., Callaway and Katz, 1993; Schubert et al., 2001). Small volumes of the slice (within $50 \mu \mathrm{m}$ ) can be selectively activated by the glutamate released by a highly focussed light beam (Yoshimura et al., 2005). The glutamate is then rapidly removed by diffusion and by uptake mechanisms. Cells in the activated area that are presynaptic to the recorded neurone and that reach firing threshold, generate postsynaptic potentials in that cell. Maps of the regions containing these presynaptic neurones can thus be generated, with relative input strengths. The structure (and therefore class) of the single postsynaptic recorded neurone is revealed by biocytin-labeling and subsequent histological processing. It is typically not possible to dissect postsynaptic responses to determine how many neurones contributed, to identify the presynaptic cell class(es) involved, or to determine unambiguously the size of each contributory input. Synaptic dynamics cannot be studied with this method since it is not clear whether later responses result from continued 
firing of the activated neurone(s), or disynaptic inputs. It does, however, provide valuable information about connections that have not been documented with other methods, particularly inputs to specific cell types from other layers, while comparisons of the relative strengths of inputs to a single neurone from many areas of the slice can be obtained very much more efficiently than with dual recordings. A recent review compares this technique with others used to study cortical circuitry (Schubert et al., 2007).

\section{Voltage-sensitive dye and $\mathrm{Ca}^{2+}$ indicator methods}

Many sophisticated protocols using these fluorescent methods have been developed over recent years and are improving in spatial and temporal resolution all the time. Their use in the definition of the fine details of circuitry has been relatively limited to date, but some valuable information, e.g., about the spread of excitation through the layers and columns when electrical stimuli are delivered at different frequencies, has resulted (Contreras and Llinas, 2001). Although not directly applicable to the building of functional microcircuits, in vivo imaging studies are now able to identify populations of supragranular layer neurones that respond to whisker movement (Civillico and Contreras, 2005, 2006), or visual stimulation (Ohki et al., 2005) with impressive three-dimensional cell structure information and will no doubt contribute significantly to this area in the future. They will also provide population data for the testing of the validity of circuit models.

Circuits of connected neurones can be studied by driving one recorded neurone to fire and using calcium imaging to identify the positions of other neurones activated by that cell (Peterlin et al., 2000). An indication of the numbers of "follower" cells in a given area of the slice that are activated by one presynaptic cell can be obtained, but they cannot be identified further and the electrophysiological properties of the synaptic events are not accessible. The obverse can also be applied, i.e., recording from one neurone, identifying the spontaneous activity of other neurones with calcium imaging and using reverse correlation to identify the putative presynaptic neurones whose activity correlated with postsynaptic potentials in the recorded cell (Aaron and Yuste, 2006). Like the caged glutamate studies, these techniques can identify regions from which significant input to the recorded cell originate. With sparse presynaptic firing, they can reveal more about the properties of individual connections, but do not identify the class(es) of presynaptic neurones involved.

Developments in imaging technology and methods such as the use of GFP labeling of specific interneuronal subclasses (see Yuste, 2005 for review) have made significant contributions to this field. Technical approaches that are being developed to improve the time and spatial resolution of scanning techniques are reviewed by Saggau (2006) and Yasuda (2006) and the ways in which techniques such as (fluorescence resonance energy transfer) (FRET) and fluorescence lifetime imaging microscopy (FLIM) may be applied to imaging molecular level events occurring in neuronal subcompartments (see Okamoto et al., 2004; Yasuda et al., 2006). Although we are still dependent upon a range of traditional techniques for most of our current understanding of circuitry, these developments in confocal and two photon technology are likely to provide considerable insight in the future.

\section{Activation of specific cell classes by a light-activated cation channel and inhibition with a light-activated chloride pump}

Transgenic mice that express the light-activated cation channel Channelrhodopsin-2 (ChR2) in subsets of neurones may provide an important tool for the future. Illumination of ChR2-positive neurones in brain slices can drive them to fire and generate postsynaptic potentials in recorded target neurones (Zhang et al., 2006). In a recent report, Chr2-YFP fusion protein was placed under the control of the regulatory elements of the mouse Thy1.2 gene and was expressed at high levels in, for example, layer 5 pyramidal cells (Wang et al., 2007). In the future, genetic targeting of ChR2 expression to different neuronal classes will allow their selective activation and the accurate mapping of the inputs from one class of neurone to one, or several recorded neurones. This will provide an advantage over the caged glutamate studies in identifying the class of presynaptic neurone involved. This approach has also been applied to functional tracing of longer distance pathways in vitro (Petreanu et al., 2007) and in vivo (Arenkiel et al., 2007). A light-activated chloride pump, NpHR, which suppresses neuronal activity, can also be transfected into specific cell classes. It can be targeted together with ChR2 which is activated at a different wavelength. Integration of these tools with calcium imaging may even provide a totally optical method for investigating circuitry in vivo (Han and Boyden, 2007; Zhang et al., 2007).

\section{Dual/multiple intracellular and whole-cell recordings of synaptically connected neurones in cortical slices}

The results obtained with these methods are the major input to the present review and the basis for much of what is included in tables and cartoons. The major limitations of this approach are the relatively small number of connections that can be studied in detail in any one experiment, the certainty (common to all brain slice studies) that many axonal branches will have been cut during the slicing procedure, the relatively poor preservation of ultrastructure in slices compared with in vivo-fixed tissue, particularly for slices maintained in submerged chambers and that neurones that have been subjected to partial denervation almost certainly make new connections within the first hour of slicing (Kirov et al., 1999). That said, the connections that the neurones exhibit in slices appear to remain extremely specific, suggesting that the new connections do not contravene the fundamental wiring rules, i.e., if/when they find new pre- or postsynaptic partners they select the cell types and subcellular compartments with which they were connected in vivo.

These methods allow the properties of the neurones and of the synaptic connections between them to be studied in some detail, under experimenter-controlled conditions. Where dye-filling, immunofluorescence, or RT-PCR and neurone reconstructions are performed, they allow the connected neurones to be unambiguously identified. The majority of such recordings have utilised two or three electrodes, but more recently, computer controlled, motorized electrode placements have enabled multielectrode recordings greatly increasing the number of connections that can be studied simultaneously (Le Be and Markram, 2006).

Hit rate estimates. The way in which "hit rates", or connectivity rates are estimated is dependent upon the method used to locate the cell pairs recorded. With dual whole-cell recordings two approaches are commonly adopted.

1. In the first approach, two neurones are viewed and selected under IRDIC (infra-red differential interference contrast microscopy) and wholecell recordings are made from both cells. One cell, then the other is brought to firing threshold to test for synaptic connections. If no synaptic connection between them is found, the cells are discarded and another two cells are selected.

2. In the second approach, one cell is recorded whole-cell and the second electrode is used to make loose patch recordings sequentially from other cells. These loosely patched cells are brought to firing threshold to test for a synaptic input to the first. When a presynaptic cell is located, it is then also recorded whole-cell with a fresh pipette.

In the first approach, the presence of synaptic connections can be tested in "both directions", while in the second a connection in the other direction will typically only be apparent once both cells are recorded wholecell. In the first case, only one cell can be tested with each potential partner, in the second, several potential presynaptic cells can be tested. It is, therefore, important to bear in mind whether the tests performed before a pair is identified are one-way or two-way, when assessing connectivity rates. 
In sharp electrode recordings, penetrations are made "blind". The cells that will be recorded cannot be selected visually and it is not possible to focus effort on one particular type of connection. Even when the layer and region are carefully targeted, many different cell types can be encountered in each recording session. It is, however, possible to make multiple penetrations with a single electrode and, therefore, to test a number of potential partners "both ways" very rapidly. The practical limit for the number of partners tested is often determined by the potential for ambiguity in the identification of dye-labeled neurones, rather than by the numbers of partners that could be sampled. In terms of the hit rate estimates obtained, therefore, this method is intermediate between the two whole-cell methods. Each pair recorded is tested both ways and multiple potential partners can be sampled for each cell held. There is then a question as to whether all dual recordings should be counted in hit rate estimations, whether or not a connection was found for the first recorded neurone. The alternative is that only those tested cell clusters that resulted in a connection should be counted. The reasoning here is that "negative clusters" may result from a poor plane of section for that type of connection, rather than a realistically low connectivity rate. In some publications both estimates have been given.

It should also be noted that the relative positions and separation of cell pairs visualized under IR-DIC, as well as the shapes of their somata, can be documented during the experiment whether or not the cells are subsequently found to be connected and processed histologically. With sharp electrode recordings, the electrode tips are not visible with light microscopy and these parameters are less accurately estimated. Sharp electrode studies of intra-laminar connections often include more widely separated cell pairs than dual whole-cell studies of the same class of connection.

Although rarely investigated in detail to date, it is a common observation that when two neurones are synaptically connected and one is connected to a third simultaneously recorded cell, the other is also connected. Thus two connected neurones are more likely to be postsynaptic targets for the same presynaptic cell than randomly selected pairs would indicate (Kampa et al., 2006) in addition, they are more likely to be presynaptic to the same target cell. A similar conclusion resulted from a study that compared quadruple recordings with a randomly connected computational model network. There was an over-representation of triplet interconnectivity and synaptic strength distributions differed significantly from the random model in resembling lognormal rather than Poisson distributions (Song et al., 2005, see also Yoshimura and Callaway, 2005).

Slice thickness also contributes to differences in hit-rate estimates. Whole-cell studies use relatively thinner slices $(300-350 \mu \mathrm{m})$ than sharp electrode studies $(450-500 \mu \mathrm{m})$. Although not studied or modelled in detail to date, we have observed significant increases in "hit rate" with increases in slice thickness from 400 to $450 \mu \mathrm{m}$ and from 450 to $500 \mu \mathrm{m}$.

Another issue is the extent to which unconnected and discarded neurones are identified. Rarely, given the time involved, are all the cells that have been tested and potentially filled with biocytin processed histologically and fully characterised morphologically and immunocytochemically. During the experiment, cells can be documented by the shape and position of the soma and proximal dendrites (whole-cell recordings under IR-DIC) and/or by their firing characteristics, but a level of ambiguity must remain.

In the longer term, the application of some of the newer techniques outlined above will no doubt provide more accurate assessments of absolute connectivity rates. Comparisons of the dendritic and axonal arbours of neurones filled in vitro with those filled in vivo and in silico "remodelling" of elements that have been cut will allow connectivity ratios obtained in slices to be corrected. For now, however, the most useful information that can be extracted is probably the differences between the connectivity rates for different types of connection, particularly when the same experimental approach is used and especially when a connection in one direction is found to display a very different rate from the connection in the opposite direction.
Comparing across different age groups and different temperatures. When the results of whole-cell and sharp electrode experiments are compared or combined, several additional factors need to be taken into account. The ease with which good whole-cell recordings can be obtained drops significantly with the age of the animal. Myelination reduces the resolution of the optics and increases the difficulty of maintaining a "clean" electrode tip required for a good seal prior to "going whole-cell". The majority of dual recording experiments with this technique, therefore, use young animals (P10-P22). A major advantage of sharp electrode studies is the facility with which adult neurones can be studied. Many cell classes can be distinguished at all these ages and the basic wiring rules, the direction of synaptic dynamics and many inherent cell properties appear to be similar to those found in the adult. However, all cellular and synaptic properties are slower at earlier developmental stages.

In a recent comparison of paired recordings in juvenile and adult rat slices (Ali et al., 2007), it was concluded that between 14-16 and 18-22 days postnatal there is a halving of the duration of synaptic potentials (comparing for example, Beierlein et al., 2003; Reyes et al., 1998), paralleled by a halving of the membrane time constant (comparing Wang et al., 2002, 2004) and the duration of APs, with some additional decrease between 3 and 6-7 weeks of age. Temperature also played a significant role with a $10^{\circ} \mathrm{C}$ increase resulting in an approximately three-fold decrease in the time course of these parameters. What was encouraging, however, was the finding that these parameters increased in parallel and that the strong correlations between inherent cell characteristics, such as AP width at half amplitude and membrane time constant and synaptic potential duration were similar for all age groups. The slower the cell's own inherent characteristics, the slower are the synaptic potentials it receives (Ali et al., 2007). Interestingly, there was also a strong correlation between the properties of the presynaptic interneurone and the duration of the IPSPS it elicited in pyramidal cells; interneurones with narrow spikes elicit fast $G_{A B A_{A}}$ receptor mediated IPSPs, interneurones with broad spikes elicit broad $\mathrm{GABA}_{\mathrm{A}}$ receptor mediated IPSPS.

Synaptic dynamics. The recording method, age of preparation, and temperature also influence the strategies commonly employed to assess the dynamic properties of connections and, therefore, the data obtained. Most paired whole-cell recordings have taken advantage of the facility with which presynaptic APs can be reliably activated by brief, large amplitude current pulses, at an interval or frequency determined by the experimenter, without compromising the postsynaptic recording. Typically, therefore, these studies select one or a few presynaptic frequencies. These frequencies are often relatively low to allow the slower postsynaptic responses typical of young tissue to subside before another is elicited.

Paired sharp electrode recordings suffer from capacitance coupling which generates artifacts in the postsynaptic recording when the flow of current in the presynaptic electrode changes. The application of brief current pulses of sufficient size to elicit APs is, therefore, not an option. Instead, longer current pulses with a range of shapes and amplitudes can be injected to generate a range of presynaptic firing frequencies and patterns and events analyzed in relation to interspike intervals and firing patterns in post hoc analysis. When both neurones are stable and recordings can be maintained for long periods (1-4 hours), large datasets that include synaptic potentials elicited with a wide range of presynaptic firing frequencies and patterns are generated. These recordings allow the fine details of the recovery from synaptic facilitation or depression to be analyzed and have revealed great complexity in the time course (Ali et al., 2007; Bannister and Thomson, 2007; Thomson and West, 2003; West et al., 2006). The use in many paired whole-cell experiments of only a few interspike intervals, typically longer than those that have yielded some interesting information in adult slices, precludes direct comparisons of these complexities across age groups. Here, therefore, the dynamic properties of well-documented connections are summarized according 
to the data available and comparisons made where similar interspike intervals have been studied.

It should also be noted that experimental conditions, such as the concentration of extracellular $\mathrm{Ca}^{2+}$, also affect release probability and dynamic properties and the reader may wish to refer to original papers to check these details. However, from the concentrations typically used in slice experiments $(2.0-2.5 \mathrm{mM})$ to the lower concentrations thought to be more physiologically accurate (e.g., $1.0 \mathrm{mM}$ free $\mathrm{Ca}^{2+}$ ), only relatively small differences in dynamic properties due to changes in the $\mathrm{Ca}^{2+}$ concentration are apparent (e.g., Thomson, 1997; Thomson et al., 1993, 1995).

\section{THE CLASSES OF}

\section{WELL-CHARACTERIZED NEOCORTICAL NEURONES INCLUDED IN THIS REVIEW \\ Thalamic afferents}

In the thalamus, a matrix of calbindin-containing relay cells projects to wide areas of cortex across cytoarchitectonic boundaries and primarily to the superficial layers (1 and 2). Superimposed on this matrix in "specific thalamic regions" are "core" regions consisting of parvalbumincontaining thalamic cells. These thalamic relay cells project to the middle cortical layer 4 and to a lesser extent lower layer 3 and to layer 6 of specific cortical regions, especially primary sensory regions, in a topographically precise manner (Jones, 1998).

Additional segregation of afferent inputs can be seen in primate primary visual cortex (V1). Axons from the "core" magnocellular layers of the LGN, with large receptive fields, project to layer 4C and layer 6 . In contrast, relay cells from the "core" parvocellular layers with small receptive fields, project to layers $4 C B, 4 A, 3 B$, and layer 6 (for review, see Lund, 1988). Layer $4 \mathrm{~B}$ receives no direct thalamocortical input. In rat barrel cortex, however, specific thalamocortical input spans the entire depth of layer 4 .

\section{Pyramidal cells}

Pyramidal cells in layer 6 . In primary sensory regions, layer 6 receives inputs from and innervates specific, sensory "core" regions (eg leaflets of the LGN and ventrobasal nuclei), as well as "non-specific" "matrix" thalamic regions and in motor cortex is reciprocally connected with the ventral posteromedial, the posterior group (Po) and the intralaminar nuclei. The claustrum, historically grouped within the basal ganglia, but not now associated with specific motor functions, is also reciprocally connected with layer 6. This layer also participates in reciprocal cortico-cortical (CC) connections, for example between the infragranular layers of motor, second somatosensory, and perirhinal cortices (Zhang and Deschenes, 1998).

Three broad categories of layer 6 pyramidal cells were described following juxta-cellular labeling in adult rat barrel cortex (Zhang and Deschenes, 1998). Two classes of cortico-thalamic (CT) cells were described. One projects to the nucleus reticularis thalami (nRT) and/or to "primary sensory" or "specific" "core" thalamic nuclei such as the ventroposterio-medial (VPm) nuclei. These upright pyramidal cells with a well-developed apical dendritic tuft and a terminal axonal arbour in layer 4 , which sometimes extends into layer 3 . Shorter CT pyramids with apical dendrites and axons that terminate in upper layer 5 , are more commonly found in deep layer 6 and project to both VPm and "non-specific" thalamic regions such as Po, but not to $\mathrm{nRT}$. Neither class of CT cells has long horizontal axon collaterals in the infra-granular layers. The majority of their axonal branches turn up toward the pia close to the soma. In primate visual cortex where distinct layer 4 subdivisions can be identified, CT cell subclasses with both dendritic branches and axonal ramifications restricted to specific sublayers of layer 4 are found (Lund, 1987; Wiser and Callaway, 1996).

The clearest distinguishing feature of layer $6 \mathrm{CC}$ cells may be that both their long, horizontally oriented axonal arbours and their dendritic trees are confined to the deep layers. The other group of layer 6 pyramids with long horizontally oriented axons in layers 5 and 6 , the claustrum projecting cells, have a long, slender apical dendrite, sometimes reaching layer 1, but without a well developed dendritic tuft in layer 4 (Katz, 1987). In contrast. the diverse dendritic morphologies of layer $6 \mathrm{CC}$ cells include short upright pyramids whose apical dendrites terminate in upper layer 5, modified and inverted pyramids and spiny bipolar cells, whose dendrites may, on occasions, project into the underlying white matter, but which do not project beyond layer 5 .

In cat visual cortex, cells with CT-like morphology are typically first order, i.e., thalamo-recipient, simple cells, while cells with CC morphology have been reported either to be second (Hirsch et al., 1998) or first order complex cells (McGuire et al., 1984). In rat primary somatosensory cortex, in addition to the thalamo-cortical input in layer 6 , retrogradely labeled CT cells received $7-20 \%$ of their synapses in layer 4 from degenerating thalamocortical axon terminals (White and Hersch, 1982). Other layer 6 pyramids received much smaller proportions of their inputs from thalamocortical afferents (White and Hersch, 1981; Hersch and White, 1981a,b).

During intracellular recordings, two broad electrophysiological groups that correlate with broad morphological categories can be distinguished in both adult rat and cat. Layer 6 pyramids with long, horizontally oriented axons and dendrites confined to in the deep layers (CC-like cells) have a very rapidly adapting firing pattern, typically firing only 2 or 3 short interval spikes in response to a suprathreshold depolarizing pulse. CT and claustrum projecting cells in contrast display a more tonic firing pattern, with some spike frequency adaptation and modest spike accommodation, but continuing to fire throughout the depolarization. The outputs of CC and CT cells also differ markedly. CC and claustrum projecting cells preferentially innervate other pyramids in layers 5 and 6 and deliver strongly depressing excitatory postsynaptic potentials (EPSPs) (Mercer et al., 2005). The hit rates for CC to pyramid connections being $4 \times$ those for CT to pyramid connections and the average EPSP amplitudes significantly larger. CT cells preferentially innervate interneurones in layer 6 and deliver facilitating inputs to both interneurones and spiny cells (West et al., 2006). They are also reported to target interneurones in layer 4 (Beierlein et al., 2003; Tarczy-Hornoch et al., 1999) and both spiny and aspiny GABAergic neurones in layers 4 and 5 (Staiger et al., 1996). The preference for interneuronal targets reported in some studies was first demonstrated in an anatomical study (White and Keller, 1987) in which CT axons synapsed mainly onto the dendritic shafts of non-spiny neurons. In striking contrast to the targets of CC axons (which preferentially innervate spines), 92\% of the contacts were onto dendritic shafts, the remainder onto spines. The facilitation seen at intracortical connections made by CT cell axons appears to be reflected in the thalamus. The EPSPs elicited in ventroposterior and posterior medial nuclei and nRT by stimuli applied to layer 6 in a thalamo-cortical slice exhibited paired pulse facilitation, while those elicited in the posterior medial nucleus from stimuli applied in layer 5 exhibited depression (Reichova and Sherman, 2004).

Pyramidal cells in layer 5. The predominant inputs to layer 5 (and to layer 5 pyramidal dendrites in layer 3) appear to be short and long range CC projections. Layer 5 pyramidal cells project to a wide range of subcortical targets, including (depending on cortical region) "non-specific" thalamic nuclei, superior colliculus, pons and spinal cord, as well as to other cortical regions and to the contralateral cortex. In cat visual cortex, corticotectal cells (projecting to regions such as the superior colliculus) are large, with a well-formed basal dendritic arbour and a long apical dendrite that forms a well-developed tuft in layers 2 and 1 . In contrast, the apical dendrites of small to medium-sized CT layer 5 cells rarely extend beyond layers 2/3 (Hubener et al., 1990). Analysis of CT axon terminals in LGN and in the lateral posterior- pulvinar complex indicated that layer 5 pyramids project in a "feed-forward" manner with large boutons, to non-reciprocal regions, i.e., those from which they receive no inputs, while layer 6 CT axons innervate reciprocally connected regions like the LGN with small boutons (Van Horn and Sherman, 2004).

Layer 5 pyramidal cells display two distinct firing patterns first described in rat cortex (Connors et al., 1982) as 'intrinsically burst 
firing" (IB) and "regular spiking" (RS) cells. The term "regular spiking" is more appropriately replaced with 'àdapting", since the firing pattern of these cells is far from regular; it displays significant spike frequency adaptation. The IB cells are large pyramids (Deuchars et al., 1994; Thomson et al., 1993) with long apical dendrites whose axons project to the superior colliculus and/or the pons (Hallman et al., 1988), while the smaller, shorter layer 5 pyramids that project to the opposite hemisphere are "non-bursters" RS or adapting cells (Kasper et al., 1994). However, not all non-bursters appeared to project inter-hemispherically and not all cells retrogradely labeled from the opposite hemisphere were found in layer 5 , indeed, trans-callosal cells were found in all layers except layer 1 (Kasper et al., 1994).

Although less precisely documented than the more recently studied connections in layer 6 , the large, burst firing pyramidal cells are more commonly the postsynaptic and smaller adapting pyramids more commonly the presynaptic partner in layer 5 pyramid-pyramid pairs, with an approximately 10 -fold hit rate difference in adult rat. These estimates are based on the firing characteristics of hundreds of tested cell pairs (unpublished estimates from studies published in Deuchars et al., 1994; Thomson et al., 1993). However, when the two pyramidal cells are very close neighbors, large layer 5 pyramids are relatively densely interconnected (Markram et al., 1997) with a hit rate of 1:10 reported for dual whole-cell studies in young rats. It is also the large layer 5 pyramids that are the major recipient of a highly focussed and extremely dense, descending excitation from layer 3 pyramidal cells. The smaller, adapting cells appear to receive little or none of this input (Thomson and Bannister, 1998).

Layer 4 spiny cells: Pyramidal cells and spiny stellate cells. Thalamocortical inputs to layer 4 involve large en-passant boutons terminating predominantly on dendritic spines, but constitute only $6 \%$ of the synapses onto spiny stellate neurones in cat V1. Layer 6 pyramidal (CT) axons, in contrast, are reported to contribute $45 \%$ of the excitatory inputs to layer 4 spiny cells via complex side-spine arrays with small boutons (in cat and primate, Lund, 1988 , for review), with $28 \%$ originating from other spiny cells in cat layer 4 (Ahmed et al., 1994). In mouse somatosensory cortex, spiny stellate cells received a larger proportion of inputs from thalamo-cortical axons (10.4 to 22.9\%; Benshalom and White, 1986). In primate $\mathrm{V} 1$, axons from area MT terminate in layers $1,4 \mathrm{~B}$, and 6 . This contrasts with other "feedback" connections from "higher" visual areas which largely terminate in layer 1. In V2, these "feedback" axons terminate primarily in layers 1 and 5 or 6 (Rockland and Knutson, 2000).

Layer 4 contains two broad classes of spiny excitatory cells: pyramidal cells with apical dendrites that extend into layer 1 and spiny stellate cells which lack apical dendrites and being largely confined to layer 4, receive most of their inputs within this layer (Lund, 1973). Some studies have been able to distinguish between spiny stellates and layer 4 pyramids, but many have not filled and identified every recorded cell, or the origin of every filled axon and with few differences between these classes being reported, some aspects of connectivity will necessarily be lumped together here.

The axons of layer 4 spiny neurones make a dense, topographically precise projection to layer 3 (and to upper layer 5 ) in rat and cat (Burkhalter, 1989; Feldman and Peters, 1978; Gilbert, 1983; Parnavelas et al., 1977; Valverde, 1976) where they innervate pyramidal cells and (rather less commonly) interneurones (Thomson et al., 2002). Both pyramidal cells and spiny stellates contribute to these projections and both provide local and horizontal projections within layer 4 . In layer 4 of cat visual cortex, some spiny cell axons make the majority of their synapses within layer 4, others form a larger proportion in layer 3 (Binzegger et al., 2004), a finding closely paralleled by morphometric analysis coupled with the results of paired recordings in rat somatosensory barrel cortex (Lubke et al., 2003). This study indicated that each layer 4 spiny neurone innervates 300-400 layer 3 pyramidal cells, with 300-400 layer
4 cells converging on each layer 3 target, while each layer 4 spiny cell is calculated to contact and to be contacted by 200 other layer 4 spiny neurones. The relatively sparse projection from layer 4 to layer 6 appears to originate more with pyramidal cells than with spiny stellate cells (unpublished).

Pyramidal cells in layer 3. In rat barrel cortex, layer 2/3 trans-callosal cells received a larger proportion of the inputs to layer 3 from the opposite hemisphere than layer 5 callosal projection neurones (Porter and White, 1986). The vast majority of the local circuit connections made by the axons of these layer 3 callosal pyramidal cells, whether in their region of origin, or in the opposite hemisphere, were onto dendritic spines $(97 \%$, where only $80 \%$ of all asymmetrical synapses were onto spines) (White and Czeiger, 1991). The striking difference in the target preference of CC cells (dendritic spines) in all layers and of CT layer 6 pyramids (shafts of aspiny dendrites) in layers 4 and 6 , is discussed further in Elhanany and White (1990). These studies provided clear evidence for pyramidal axon target preference, evidence that has often been ignored in more recent functional and theoretical studies.

Layer 3 pyramidal cells can also receive thalamo-cortical inputs from primary sensory thalamus, largely to their basal dendrites in layer 4, but the further their somata are from layer 4, the weaker this input becomes (White and Hersch, 1981). In extrastriate visual areas, a projection from the pulvinar (the most caudal thalamic group) innervates predominantly layer 3 with branches of the main axons providing less dense innervation of other layers (Rockland et al., 1999).

Layer 3 pyramidal cell axons ramify densely in layers 3 and 2 and send a descending axon to layer 5 where they ramify, in rat (Lorente de Nó, 1922; Burkhalter, 1989), cat (0’Leary, 1941; Gilbert and Wiesel, 1983; Kisvárday et al., 1986) and primate (Spatz et al., 1970; Lund et al., 1993; Yoshioka et al., 1994; Kritzer and Goldman-Rakic, 1995; Fujita and Fujita, 1996). These descending axons typically pass through layer 4 without ramifying there. In primate visual, motor and somatosensory cortex, layer 3 (and to a lesser extent layer 5) cells are also a prominent source of lateral CC connections providing dense innervation of patches of cortex a few hundred microns wide and up to a few millimetres from the injection site within layers 1-3 (Levitt et al., 1994), while in prefrontal cortex, a narrow stripe-like, rather than a patchy pattern is apparent (Levitt et al., 1993).

\section{Inhibitory GABAergic Interneurones}

It continues to be a matter for intense debate both how interneurones in the neocortex should be classified and how many different classes there are. That there are many classes is indicated by the classification of hippocampal interneurones. In this simpler cortical structure that includes only one layer of pyramidal cells, more than 16 different classes of inhibitory GABAergic interneurones have been identified. The criteria used include the position of their somata, the layer(s) through which their dendrites extend and therefore, the intrinsic axons and afferent pathways from which they might receive input and the layer(s) in which their axons ramify. In hippocampus, the layer(s) innervated by the interneurones identify the pyramidal subcellular compartments inhibited by them; basket cell axons ramifying in stratum pyramidale innervate somata and proximal dendrites, chandelier or axo-axonic cells ramifying in one half of stratum pyramidale and adjacent proximal stratum oriens innervate axon initial segments, while a wide range of classes of interneurones innervate pyramidal dendritic regions in straum oriens, stratum radiatum, and stratum lacunosum moleculare. Interneuronal neurochemistry also correlates with these structural characteristics, while the firing patterns of CA1 interneurones during theta activity and sharp waves correlate closely with their other characteristics (reviewed in Somogyi and Klausberger, 2005).

Some of the major classes of CA1 interneurones have direct correlates in neocortex and neurochemical classification schemes transfer 
Presynaptic Excitatory Cells

Postsynaptic Excitatory Cells

Excitatory Cells Receiving little/no input

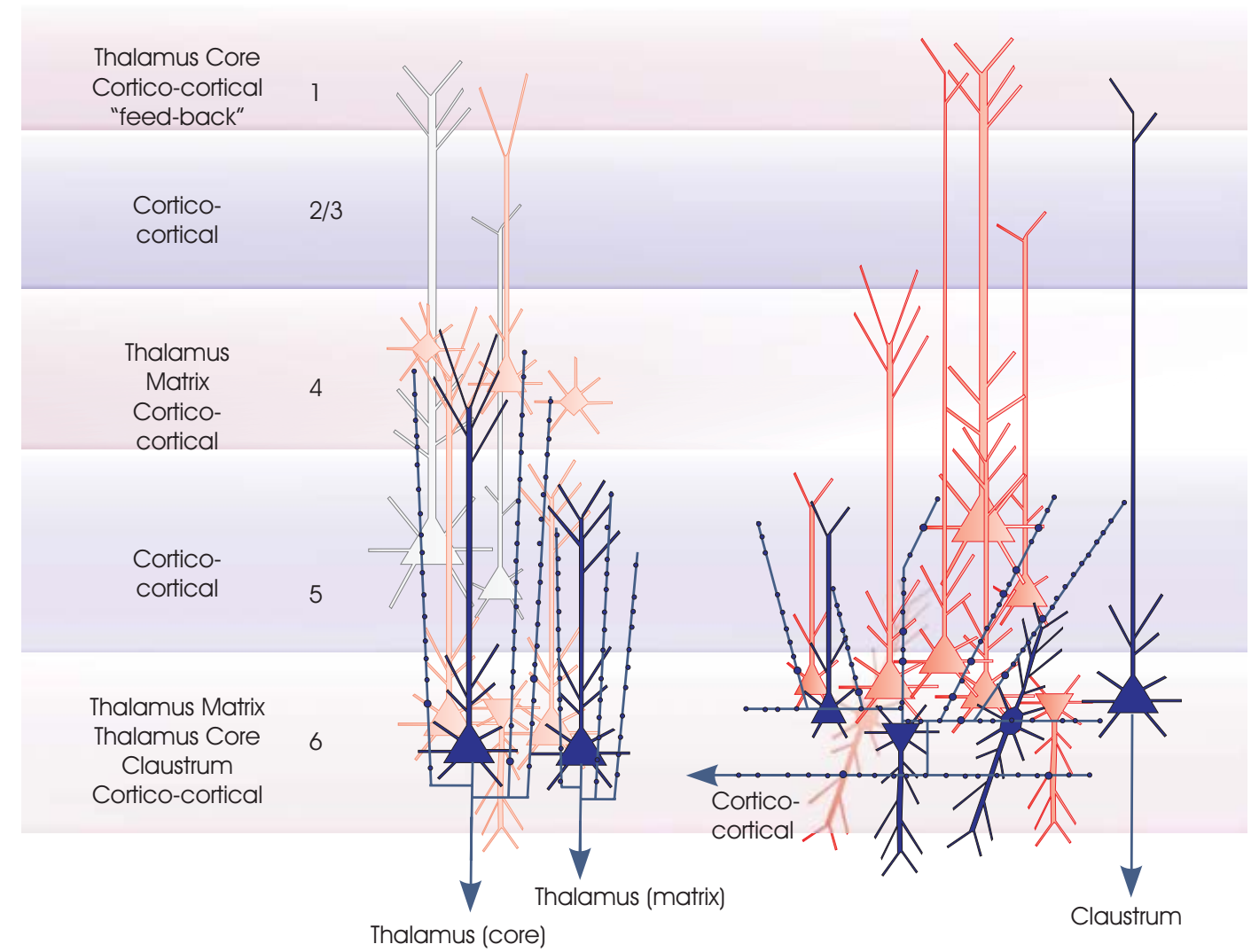

Nucleus Reticularis Thalami

Figure 1. Layer 6 pyramidal cells. The major subclasses of layer 6 pyramidal cells are summarized in this cartoon (blue). On the left are the two types of CT pyramids projecting to different regions of the thalamus. Both are upright pyramids with apical dendritic tufts and narrow, vertically projecting axonal arbours in layer 4 and upper layer 5, respectively. Three dendritic arbours typical of CC pyramidal cells, short upright, inverted and bipolar, are shown and a claustrum projecting cell (far right). Only one horizontally oriented axonal arbour confined to the deep layers is indicated for simplicity, since all CC cells and claustrum projecting cells appear to have similar axonal arbours. The major longer distance inputs to the 6 layers are indicated to the left. Spiny, excitatory postsynaptic targets that have been demonstrated for each group of layer 6 cells with paired intracellular recordings are shown in red, the paler cells being those that receive sparse and weak inputs and the white cells those that have been tested but not to date shown to be significant targets for these layer 6 pyramidal axons .

relatively well between regions. For example, an analysis of the calcium binding protein and neuropeptide content of different classes of neocortical interneurones demonstrated strong correlations between neurochemical marker expression and gross morphology (Toledo-Rodriguez et al., 2005; Monyer and Markram, 2004). The multilayered structure of the neocortex precludes a classification based solely upon the layer(s) in which their axons and dendrites lie., All layers between 2 and 6 include the somata, basal and apical dendrites and axon initial segments of pyramidal cells, so the fact that an interneurone innervates a particular layer does not indicate which cells or which subcellular compartments it innervates. The functional relevance of its axon terminals in that layer depends on its targets and on their role.

Interneurones receiving thalamo-cortical inputs. A growing body of evidence gained from intracellular recordings in vivo during responses to sensory stimuli indicate that some inhibitory interneurones are activated very early in such responses (e.g., Borg-Graham et al., 1998; Porter et al., 2001) and are, therefore, likely to be directly thalamorecipient. That GABAergic neurones were amongst the targets of thalamic afferents (Freund et al., 1985) and that they include both parvalbumin-
(PV-) immunopositive (Staiger et al., 1996) and vasoactive intestinal polypeptide- (VIP-) immunopositive cells (Hajos et al., 1997; Staiger et al., 1997) was demonstrated by ultrastructural studies in rat. In thalamocortical slices, fast, depressing EPSPs are activated in fast spiking (putative PV-containing) layer 4 interneurones by electrical stimulation of the thalamus, but little, or no input to LTS (low threshold spiking, putative somatostatin- or SOM-containing) interneurones is activated (Beierlein et al., 2003).

As summarised below, the majority of PV-containing interneurones target proximal regions of pyramidal cells (basket and chandelier cells). Basket cells, even those in layer 4 containing PV, are however, a widely disparate group, differing in size and axonal ramification. Neurones containing VIP are also a non-homogeneous group, including two subclasses of bipolar cells (one of which is dendrite targeting, the other possibly an interneurone-specific subtype, see below) and small basket cells that contain VIP and CCK (cholecystokinin). Whether all these subtypes receive thalamo-cortical input remains unclear.

Basket cells. In general terms, interneurones that stain heavily for the calcium binding protein parvalbumin (PV), target very proximal regions of 


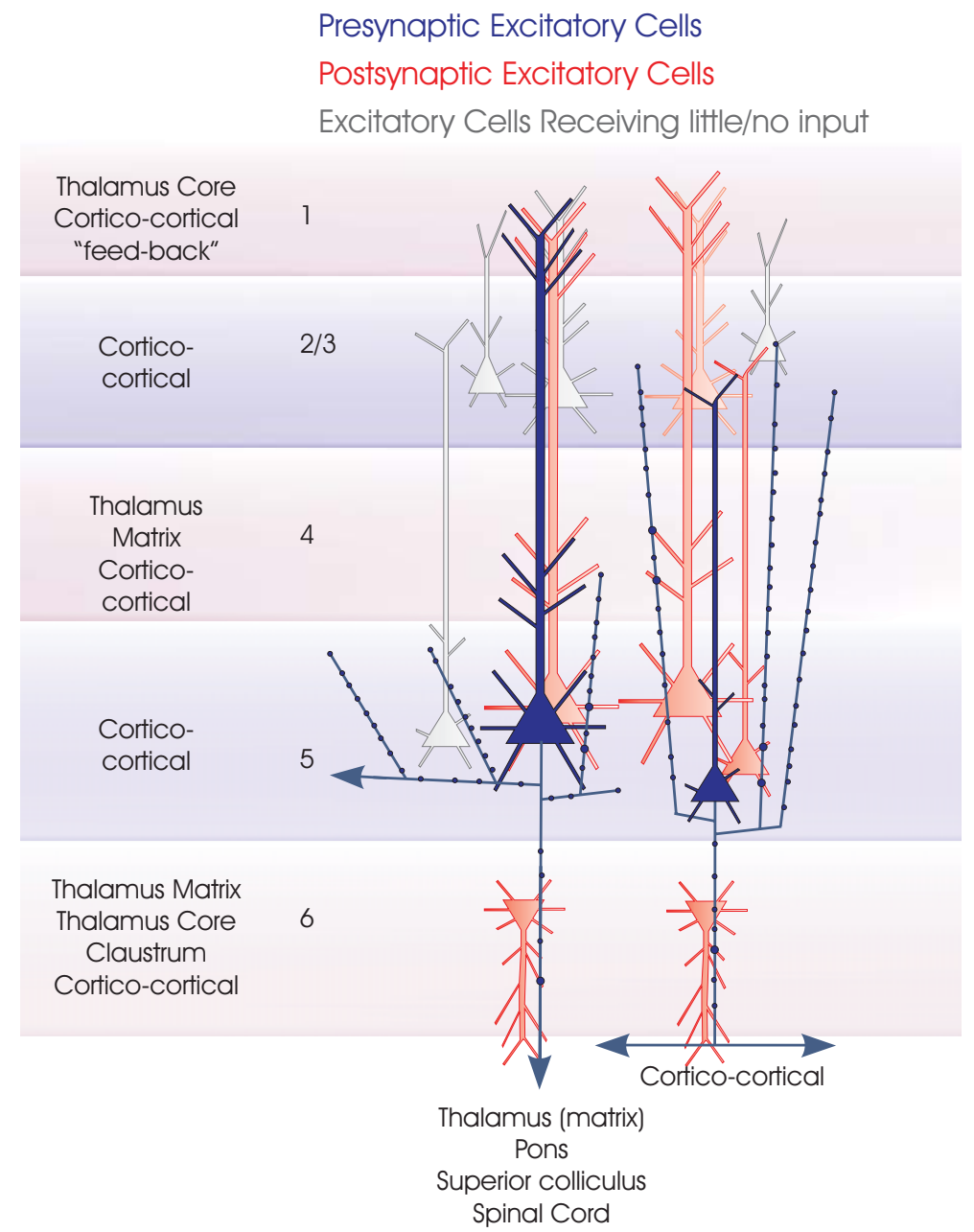

Figure 2. Layer 5 pyramidal cells. The two major subclasses of layer 5 pyramidal cells are summarized in this cartoon (blue). Large pyramids with a pronounced apical dendritic tuft in layers 1 and 2 project to several subcortical regions, while small, shorter pyramids include CC cells. The major inputs to each layer are indicated to the left. Spiny, excitatory postsynaptic targets that have been demonstrated with paired intracellular recordings are shown in red, the paler cells being those that receive sparse and weak inputs and the white cells those that have been tested but not to date shown to be significant targets for these axons. Where a class of spiny excitatory cell is not indicated in a particular layer, it has not been tested sufficiently often with layer 5 pyramidal cells in paired recordings to determine whether the connection exists.

pyramidal cells: their somata and proximal dendrites (basket cells, e.g., Kawaguchi and Kubota, 1993; Kawaguchi, 1993; Condé et al., 1994, but see multipolar burst firing cells below) and their axon initial segments (chandelier cells). These interneurones typically display a "fast spiking", (FS) firing pattern with narrow action potentials (APs), deep fast spike afterhyperpolarizations (AHPs) little spike accommodation, or frequency adaptation and are able to maintain high maximal firing frequencies. These firing patterns can, however, include a range of additional features such as "stuttering" or 'ìnterrupting" patterns driven by subthreshold membrane potential oscillations and delayed firing onset (see also Gupta et al., 2000). Without unambiguous identification of targets it is not possible to classify a cell absolutely as a basket cell, but many studies have relied on the overall resemblance of the cells recorded to basket cells that have been positively identified in other studies. It should also be noted that some studies refer to all neurones with a fast spiking behavior as basket cells, whether or not their morphology has been studied. These inaccuracies have led to some discrepancies in the literature and wherever possible here the way in which a neurone has been classified, or the properties that have been adequately documented are indicated. In many cases basket (and chandelier) cells are multipolar interneurones with dendrites radiating in all directions from the soma. They typically have partially myelinated axons that bear large boutons.

Typically, PV-basket cells receive fast, depressing EPSPs from and deliver fast, proximal IPSPs to pyramidal cells (Ali et al., 2007). Fast spiking cells in barrel cortex receive fast, short latency EPSPs in response to principal whisker movement in vivo. The fast inhibition they activate across columns and layers, their subthreshold membrane potential oscillations and rhythmic firing at gamma frequencies, entrained by the very fast IPSPS they receive from other interneurones, also suggest their involvement in these rhythms (Whittington et al., 2000).

Other proximally targeting cells include basket cells immunoreactive for CCK. These typically display broader APs than PV-baskets and an adapting and accommodating firing pattern. They receive slower, depressing EPSPs from and deliver slower IPSPs to neighboring pyramids. CCKcontaining cells are quite distinct from PV-cells, being a primary recipient of 5-hydroxytryptamine (5-HT) synapses, unique in expressing 5-HT3 and nicotinic $(\alpha 7)$ receptors (Blatow et al., 2005) and with calbindin (Cb)interneurones, unique in bearing presynaptic CB1 (cannabinoid type 1) 


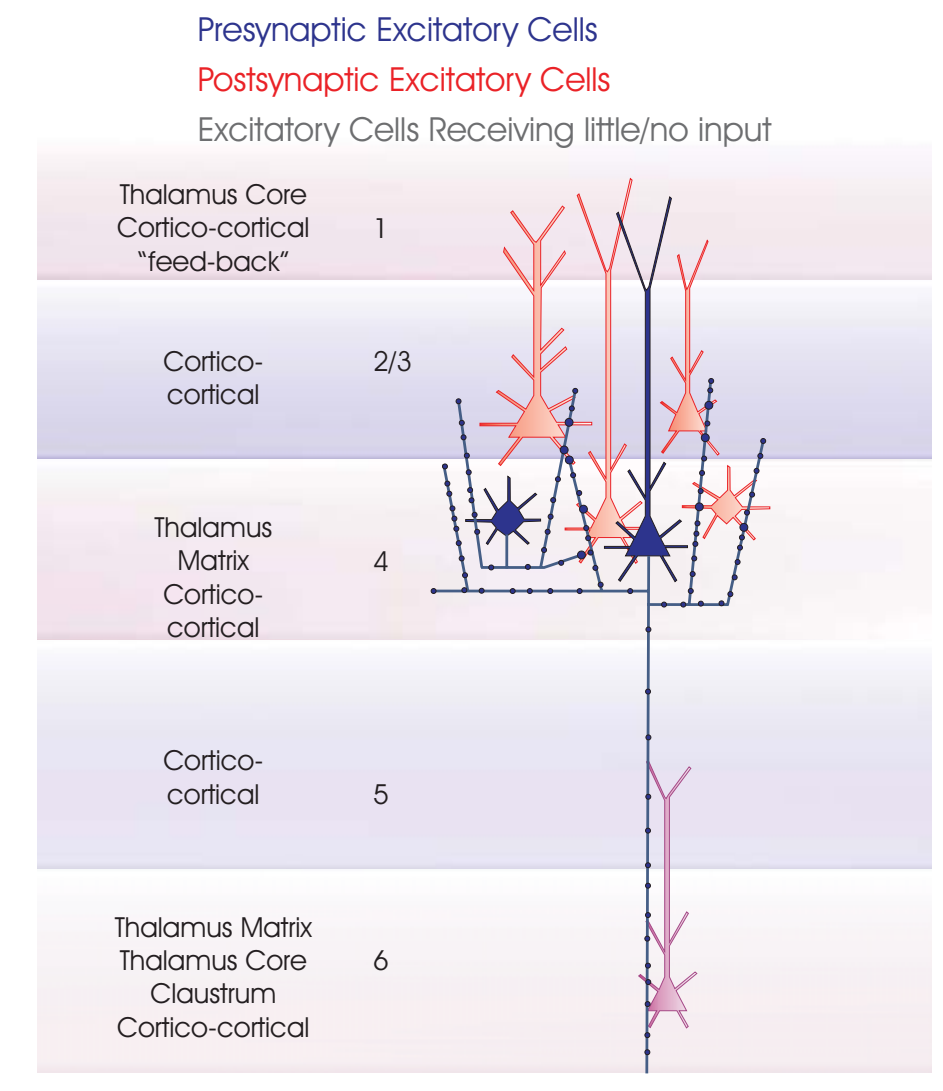

Figure 3. Layer 4 spiny excitatory cells. The two major subclasses of layer 4 spiny excitatory cells, pyramidal cells and spiny stellates are summarized in this cartoon (blue). The major inputs to each layer are indicated to the left. Spiny, excitatory postsynaptic targets that have been demonstrated with paired intracellular recordings are shown in red, the purple cell indicates a connection that has been demonstrated, but for which there are too few examples to identify target cell class(es) fully. Where a class of spiny excitatory cell is not indicated in a particular layer, it has not been tested sufficiently often with layer 4 spiny cells in paired recordings to determine whether the connection exists.

receptors (Katona et al., 1999). In a detailed comparison of the properties of small and large basket cells in young rats, Wang et al. (2002) also described a class of nest basket cells with intermediate axonal density. Small baskets typically contained mRNA for CCK and VIP, with only a minority expressing mRNA for PV. Large and nest baskets contained PV or calbindin and CCK, but not VIP.

Small basket cells have dendrites and densely ramifying axons that are often confined to their layer of origin. These include clutch cells (Kisvarday et al., 1986) most commonly associated with layer 4 . Some clutch cells have their soma and some dendrites in layer 5 , but all have a dense axonal arbour largely restricted to layer 4 . Large basket cell dendrites can span 2-3 layers and their axons can extend horizontally for long distances. In cat visual cortex these axons can be up to $3 \mathrm{~mm}$ in length and provide clustered input to discrete regions representing the whole range of orientations (e.g., Kisvarday and Eysel, 1993). Large basket cell axons can also extend vertically, ramifying in 2 or more, often non-adjacent layers (Ali et al., 2007; Thomson et al., 2002). These projections can be highly sublayer-specific, for example, in primate prefrontal cortex, basket cells in layer $5 \mathrm{~B}$ project to layers $2 / 3 \mathrm{~A}$, while layer 6 basket cell axons project to layer $4 \mathrm{C}, 4 \mathrm{~A}$, and $3 \mathrm{~B}$. These axonal projections parallel the patterns of apical dendritic and recurrent axon projections of pyramidal neurones lying within the layer of origin (Lund et al., 1988). Large baskets both in layer 3 and in layer 5 can have axons that ramify densely in both these layers, but not in layer 4 , while in contrast, large layer 4 basket cells can project to layer 6 with little ramification in layer 5 , although some ramify approximately equally in all three layers.
Chandelier or axo-axonic cells. Chandelier cells are, from the shape of their axonal arbours, arguably the most readily identifiable interneuronal class. They innervate, almost exclusively, the axon initial segments of pyramidal cells (Somogyi, 1977), forming short, vertically oriented axonal branches from major myelinated branches. These short, terminal branches, or cartridges, form large boutons on axon initial segments in one or more often non-adjacent layers or sublayers, e.g., in layers $4 \mathrm{C}$ and $5 \mathrm{~A}$ in primate visual cortex (Lund, 1987). Cartridges immunoreactive for PV and cartridges immunoreactive for corticotrophin releasing factor (CRF) have been described with differing laminar distributions in different cortical regions in primate (Lewis and Lund, 1990). In layer 2/3 of rat barrel cortex, these interneurones have large receptive fields with longer latency excitatory and shorter latency inhibitory field components than other layer 2/3 cells (Zhu et al., 2004). The GABAergic IPSPs elicited by these interneurones may display unique properties that result in part from the specific structure and function of the axon initial segment (Howard et al., 2005; Tamás and Szabadics, 2004). Among these are the proposed excitatory effects of IPSPs elicited by chandelier cells, which may result from differential distributions of chloride transporters (Szabadics et al., 2006).

\section{Dendrite-preferring Interneurones.}

Bitufted dendrite-preferring SOM-containing interneurones. Bitufted interneurones have oval or spindle-shaped somata with all dendrites issuing from the apical and basal poles. Their axons are typically finer than those of PV-cells and have smaller boutons which target pyramidal 


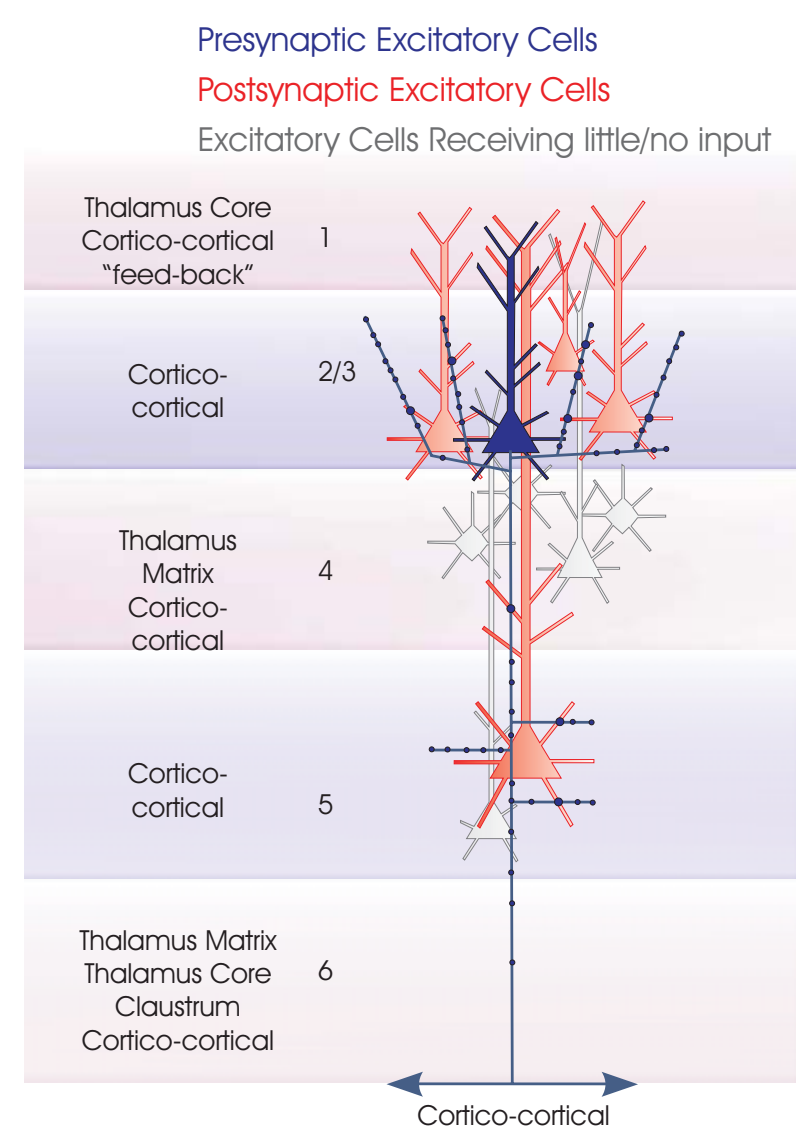

Figure 4. Layer 2/3 pyramidal cells. Layer 3 pyramidal cells are summarized in this cartoon (blue). The major inputs to each layer are indicated to the left. Spiny, excitatory postsynaptic targets that have been demonstrated with paired intracellular recordings are shown in red and the white cells indicate those that have been tested but not to date shown to be significant targets for these axons. Where a class of spiny excitatory cell is not indicated in a particular layer, it has not been tested sufficiently often with layer 3 pyramidal cells in paired recordings to determine whether or to what extent the connection exists. To date the majority of paired recordings have involved layer 3 pyramids. The outputs of layer 2 pyramids remain to be studied in detail.

dendrites. They are typically somatostatin (SOM) immunoreactive and exist in all layers, although the distributions of the several subtypes differ across layers.

SOM-positive Martinotti cells (Condé et al., 1994; Fairén et al., 1984 Gabbott etal., 1997; Kawaguchi and Kubota, 1993, 1997, 1998; Martinotti, 1889) have fine axons that ramify densely within, and in all layers superficial to the layer of origin innervating dendrites and dendritic spines. A significant axonal arbour in layer 1 is a necessary distinguishing feature for this class. A detailed description of Martinotti-like cells in layers 2-6 of rat cortex, their expression of common interneuronal markers and of ion channels (single cell multiplex RT-PCR) demonstrated that all were positive for SOM and negative for PV and VIP. Expression of mRNA for Cb, CR, NPY (neuropeptide Y), and CCK varied (Wang et al., 2004).

Double bouquet cells (Somogyi and Cowey, 1984) in addition to containing SOM, are described variously as containing calbindin, (Condé et al., 1994), sometimes colocalized with calretinin (Del Rio and De Felipe, 1997) and neuropeptides such as VIP (Kawaguchi and Kubota, 1997) and CCK (Freund et al., 1986) in various combinations. They have a dense axonal arbour in the layer of origin (layers 3 or 4; Tamas et al., 1998) and a narrow "mare's tail" of vertically oriented axons that descend through all deeper layers innervating predominantly dendritic spines and shafts (Freund et al., 1986).

Other bitufted SOM-containing, LTS bitufted cells with less stereotypical axonal arbours, can be found in all layers. Their axons typically ramify less densely than those of Martinotti or double bouquet cells and extend both above and below the soma, often into adjacent layers, but rarely into layer 1 . These cells may have sparsely spiny dendrites in the adult and in young animals can be densely spiny.

A recent comparison of the structure of interneurones labeled by GFP expression under the control of the GAD-67 promoter gene in three different mouse lines demonstrates that subclasses of SOMimmunopositive interneurones are quite distinct (Ma et al., 2006). In all three mouse lines, the GFP cells exhibited spike frequency adaptation and accommodation, but patterns varied. In the one mouse line (X98), the GFP expressing cells exhibited LTS behavior. These cells were found in layers 5 and 6 and were calbindin- (and sometimes NPY-) positive, Martinotti-like, cells. In another mouse (GIN), calbindin-negative SOM cells expressed GFP. These were also, Martinotti-like adapting cells, but with weak LTS characteristics and found predominantly in layers 2-4. In the third mouse (X94), the GFP expressing SOM cells were found predominantly in layers 4 and 5 . They had a dense local axonal arbour that did not extend to layer 1, faster APs than the other two classes and displayed a stuttering firing pattern rather than LTS behavior.

In layer 4, LTS cells with spindle-shaped somata receive little if any direct thalamocortical input (Beierlein et al., 2003). All 3-4 classes of SOMcontaining interneurones studied to date and in all layers, received broader, facilitating EPSPs from local pyramids and delivered slower, GABA $A_{A} R$ IPSPS to pyramidal dendrites than basket cells (Ali et al., 2007; Silberberg et al., 2007; Thomson et al., 1995). As perhaps predictable from their lack of direct thalamic input and their "low $p$ " facilitating inputs from pyramids, their responses to principal whisker stimulation have much longer latencies than those in fast spiking cells.

Although the presynaptic cell class could not be identified, an elegant ultrastructural study of the spine neck targets of GABAergic boutons demonstrated that VGLUT2-positive thalamo-cortical bouton-recipient spines bear inhibitory inputs. In contrast, VGLUT1 positive CC boutonrecipient spines only received a single excitatory synapse (Kubota et al., 2007).

Bipolar dendrite-preferring VIP-containing interneurones. In addition to PV-containing interneurones (Staiger et al., 1996), VIP containing interneurones, are the major thalamo-recipient class in layer 4 (Hajos et al., 1997; Staiger et al., 1997). It remains to be determined whether both bipolar and VIP/CCK containing cells are targets of thalamic afferents. VIP-containing, stuttering bipolar cells are relatively sparsely distributed and found largely in layers 2-4. One class of bipolar cells constitutes an exception to an otherwise consistent relationship; that interneurones with fast APs, receive fast depressing EPSPs, while interneurones with broad APs, receive broad, facilitating EPSPs (Ali et al., 2007). Bipolar cells have broad APs, receive broad EPSPs and deliver broad IPSPs to pyramidal cells, but the EPSPs they receive often demonstrate strong depression (Ali et al., 2007; Porter et al., 1998; Rozov et al., 2001) and are, therefore, most effective early in a presynaptic spike train. The slow GABA $_{A}$ IPSPs they deliver may contribute to dendritic receptive field inhibition in a particular time window.

Two populations of bipolar interneurones, those that express calretinin (CR) and/or choline acetyltransferase (ChAT) and those that express neither, can also be distinguished by the duration of continuous firing before stuttering/interrupting starts, the ChAT/CR negative cells firing for longer (Porter et al., 1998). Unlike ChAT/CR negative cells, ChAT/CR positive cells have been reported to received EPSPs that facilitate. No IPSPS were elicited by these cells in simultaneously recorded pyramids, but in 
2:40 tested pairs, IPSPs were elicited in neighboring interneurones (von Engelhardt et al., 2007). Whether this subclass of VIP/CR/ChAT-bipolar cells represents an interneurone-specific class of interneurones similar to the VIP/CR cells in hippocampus (Gulyas et al., 1996) remains to be determined.

Both types receive inputs from 5-HT-containing fibres, while the VIP/ChAT containing cells received more cholinergic input than the ChATnegative bipolars (Cauli et al., 2004).

Neurogliaform cells. Another interneurone class that displays distinctive morphology is the neurogliaform or spider-web interneurone, found most commonly in layer 4 in sensory cortical regions. These cells have small round somata, short radial dendrites and fine, densely ramifying "èntangled" axonal arbours 300-400 $\mu \mathrm{m}$ in diameter (Jones, 1984; Kisvárday et al., 1990). They are immuno-positive for calbindin (Gabbott et al., 1997), alpha-actin-2 (Uematsu et al., 2007), ChAT and immunonegative for PV, SOM, and VIP. Neurogliaform cells exhibit a late spiking behavior in rat (Kawaguchi and Kubota, 1997), but no delay in primate (Povysheva et al., 2007) and deliver mixed $\mathrm{GABA}_{A}$ - and $\mathrm{GABA}_{B}$-receptor mediated inhibition to the heads and necks of dendritic spines and to dendrite shafts of pyramidal cells. These cells are so far unique in being able to elicit a $\mathrm{GABA}_{B}$-receptor mediated event with a single spike, i.e., without repetitive firing or the cooperation of other interneurones (Tamás et al., 2003, see Thomson and Destexhe, 1999 for discussion). They are also densely interconnected with other interneurones via gap junctions (Simon et al., 2005).

Dendrite-preferring Multipolar Burst Firing interneurones. A subclass of multipolar, PV-positive interneurones, with action potentials as narrow as those of neighboring fast spiking multipolar interneurones is found close to the layer $1 / 2$ border. Like other PV-interneurones, these cells receive depressing EPSPs from neighboring pyramid, but differ from other PVinterneurones in their preference for dendrites and dendritic spines as postsynaptic targets, the burst firing pattern that they display, in their co-expression of calbindin and in the facilitation displayed by the IPSPS they generate in pyramids as well as in other interneurones (Blatow et al., 2003).

Interneurones and the control of vascular tone. There is growing evidence that some classes of GABAergic interneurones control blood flow in their locality. The firing of even of a single interneurone can cause either the dilation or constriction of neighboring blood vessels. Single cell RTPCR identified the cells that caused dilation as those containing nitric oxide synthase (NOS) and/or VIP, while those that caused constriction expressed mRNA for SOM (Cauli et al., 2004). This suggests that an important, or even the major role for some interneurones is not inhibition of other neurones, but an integration of many incoming signals to generate an output that ensures adequate supply of nutrients and removal of metabolites. The suggestion that GABAergic inhibition is not the primary role of all interneurones is also suggested by the finding that neurogliaform cells, which can provide powerful mixed $G A B A_{A} / G A B A_{B}$ IPSPs to neighboring pyramids, can only do this at a very low rate. The IPSPs decline dramatically with repetition unless the rate is reduced to one spike per 90 second (Tamás et al., 2003).

\section{CELL CLASSES - SUMMARY}

\section{Spiny, excitatory neurones}

There are, therefore, at least three classes of pyramidal cells in layer 6 (CC cells, CT cells, and claustrum projecting cells), at least two in layer 5 (small CC cells and large cells that project to subcortical structures such as the superior colliculus) and both spiny stellates and pyramidal cells in layer 4 . Whether distinct subtypes of layer 3 pyramidal cells exist has not been as thoroughly documented, but there is certainly a range of sizes and the cells in lower layer $3(3 \mathrm{~B})$ receive thalamo-cortical input in some regions and species.

\section{Inhibitory interneurones}

Interneurones that preferentially target proximal regions of pyramidal cells. These include basket cells with three distinct neurochemical profiles: large baskets and nest baskets contain either PV or CCK, but not VIP and small baskets that are more commonly positive for both CCK and VIP. Although large CCK- and PV-baskets are similar in axonal and dendritic profiles, they constitute distinct functional entities since their firing patterns, their inputs and the time course of their outputs differ significantly. In hippocampus, despite the almost identical structure of stratum pyramidale CCK- and PV-baskets, the phase relationships of their firing to theta rhythms and sharp waves are quite different (Klausberger et al., 2005). The final class of interneurones that target proximal regions of pyramidal cells and can silence firing, are the chandelier or axo-axonic cells that innervate the axon initial segments of pyramidal cells. Whether PV- and CRF- containing chandelier cells constitute functionally distinct entities remains to be addressed.

\section{Interneurones that preferentially innervate pyramidal dendrites.}

These include the bitufted, typically SOM-containing interneurones which fall into at least 3 major groups; the Martinotti or Martinotti-like cells, the double bouquet cells and the bitufted cells with less distinctive axonal arbours. Studies of genetically modified mice and RT-PCR studies in young rats suggest that there may be two subclasses of Martinotti-like cells, those in the deep layers that also contain calbindin and those in the superficial layers that do not. Bipolar interneurones, which are more common in layers 2-4 and typically contain VIP, also target dendrites. Again, there may be two distinct classes, those that contain CR and ChAT and may be interneurone-specific and those that do not. Neurogliaform cells form a distinctive group of small dendrite-preferring interneurones, unique in being able to generate $\mathrm{GABA}_{B}$ receptor mediated IPSPs in their targets with a single spike and densely interconnected with other interneurones via gap junctions. Finally, a class of PV-containing, burst firing, dendritepreferring cells, the multipolar burst firing interneurones have recently been described.

At a conservative estimate, with 2-3 different classes of excitatory and at least 8-10 different classes of inhibitory cells in each layer there is the potential for more than 100 different types of synaptic connection within each layer and many more if interlaminar connections are included. Unfortunately, we do not have precise data for all of these classes, however, some are of very low incidence and could possibly be ignored in simple wiring diagrams until their functional relevance is ascertained, others are necessarily "lumped" until more specific data are available.

\section{EXCITATORY CONNECTIONS BETWEEN SPINY CELLS}

The general principle that has emerged from paired recordings is that there is an almost unidirectional flow of excitation within a cortical microcircuit. Layer 4 projects to layer 3 and layer 3 to layer 5 . Excitatory connections to excitatory cells in the opposite direction, from layer 3 to layer 4 and from 5 to 3 are infrequent and weak. In contrast, these "back projections" involve inhibitory interneurones, either via the axons of the inhibitory cells themselves, or via excitatory inputs to interneurones in the recipient layers. This simple connectivity map is illustrated in Figures 5 and 6 where connections that have been demonstrated by paired recordings are shown.

The tables summarize the hit rates, amplitudes and time course for the EPSPs recorded with dual sharp and dual whole-cell recordings. Readers are referred to the papers cited in these tables for further details. Some properties are shared by many of these connections. For example, with the exception of the outputs of layer 6 CT cells and connections between pyramidal cells with dual apical dendrites in the prefrontal cortex (Wang et al., 2006), the majority of connections between spiny excitatory cells display paired pulse and brief train depression, a time course that is significantly longer than those of EPSPs recorded in most interneurones and a non-linear voltage relation and pharmacology indicative of an NMDA 


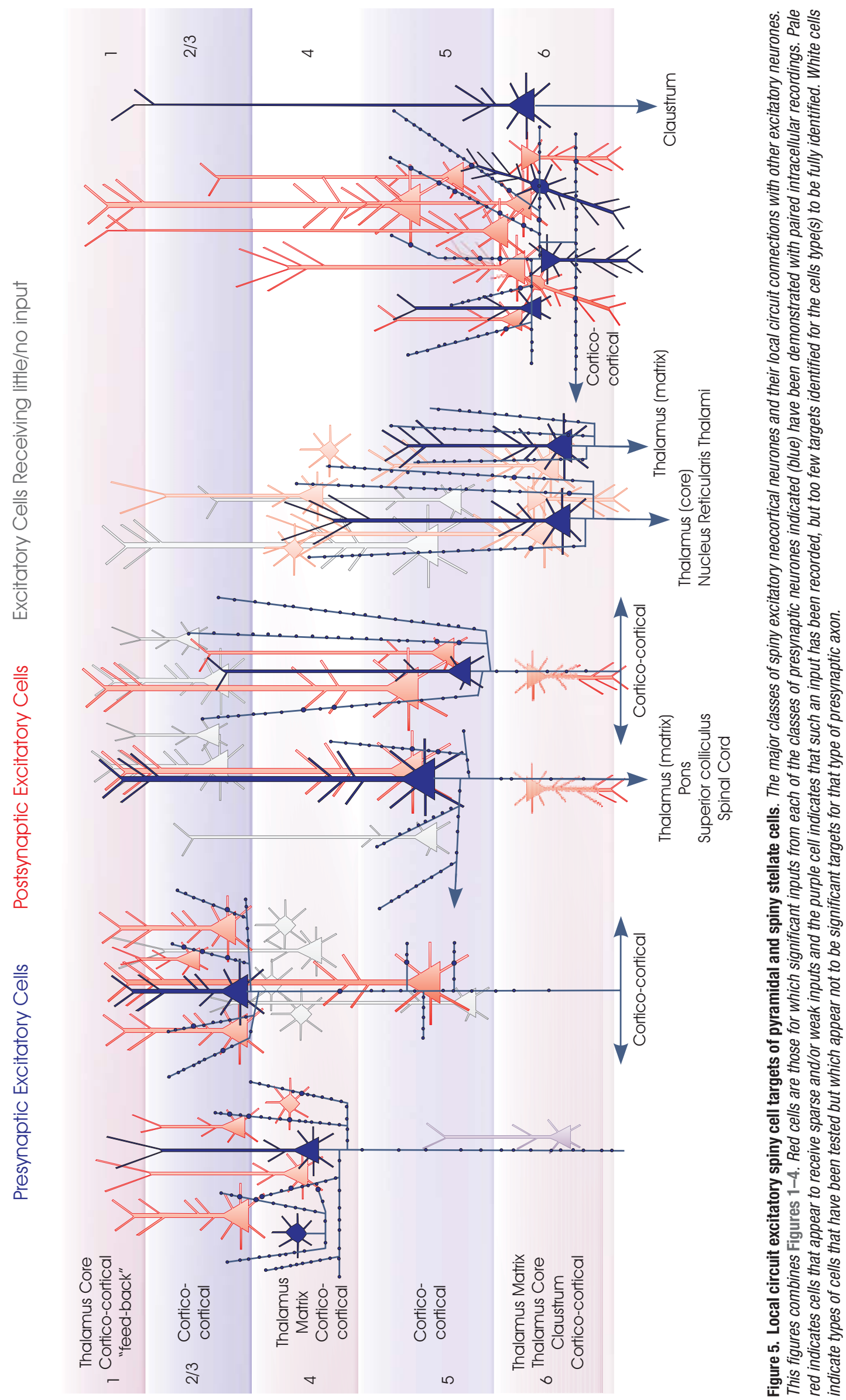




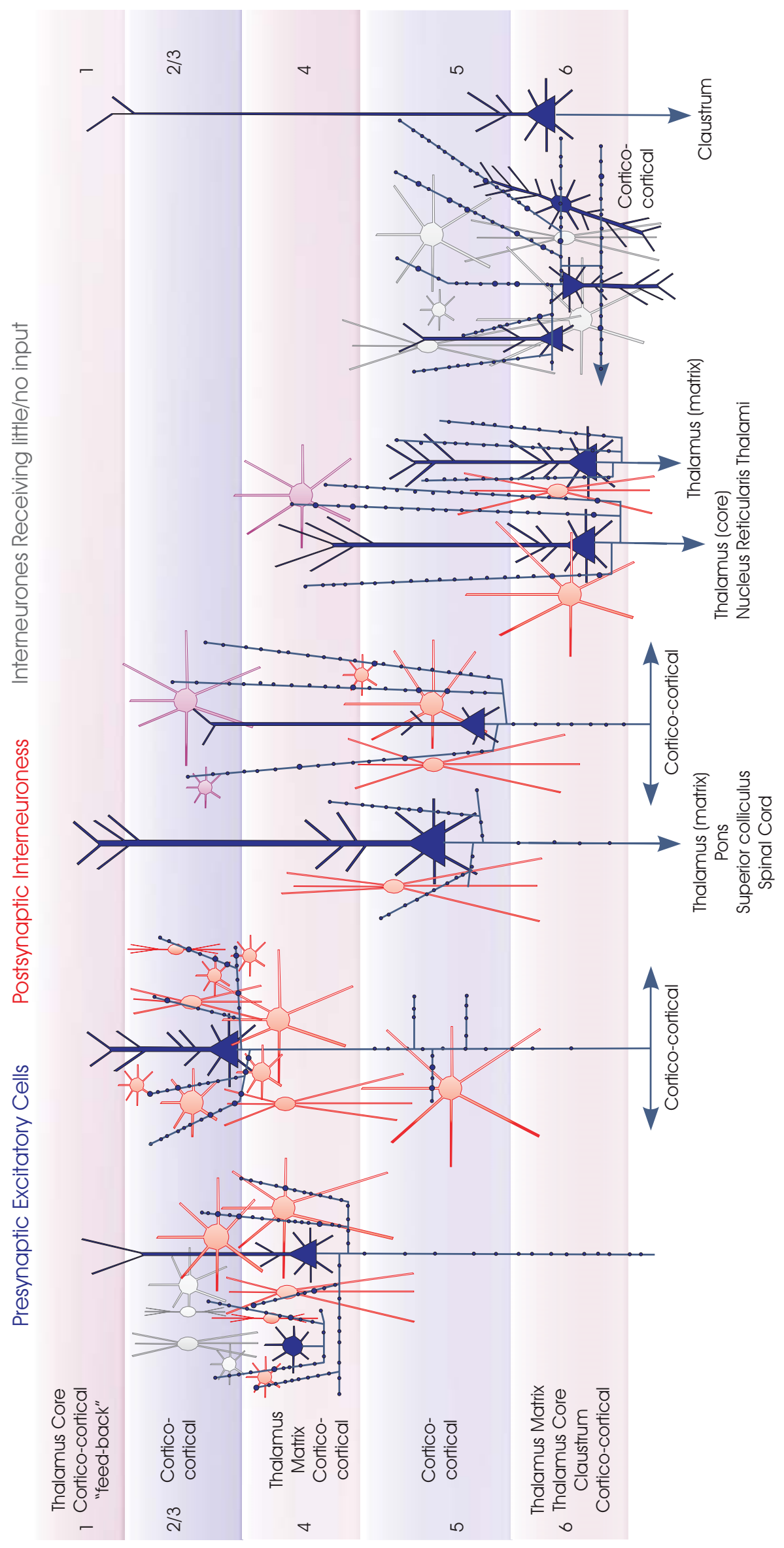

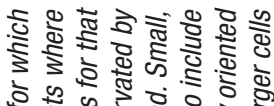

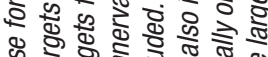
क्ष

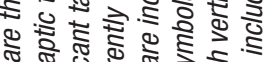
क्ष

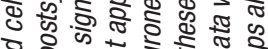

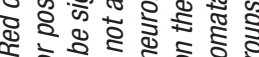

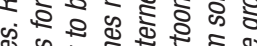

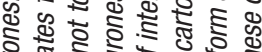

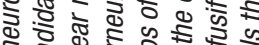
s.

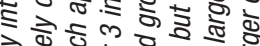

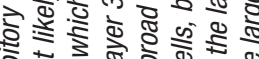
일

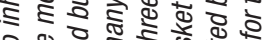
语焉 ह क⿺辶一兀

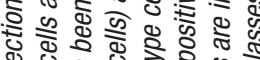

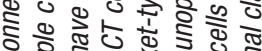

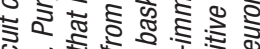
क्ष

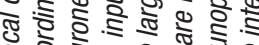

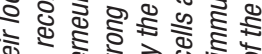
क्षे

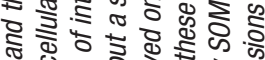

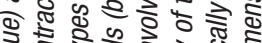

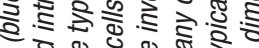

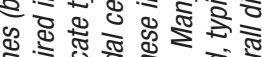

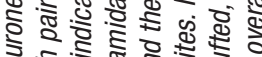

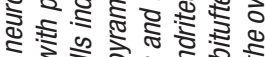
秀 卷 :

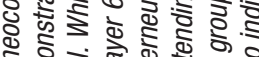

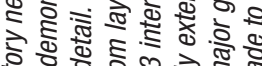
(

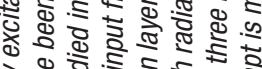

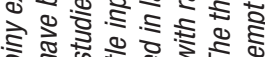

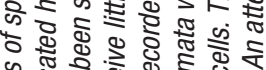
क्ष

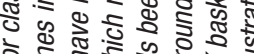

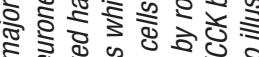
는 는 ต

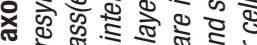
电运

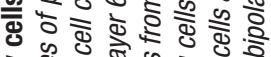

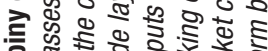
क

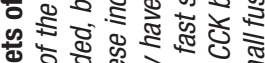

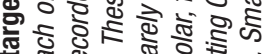

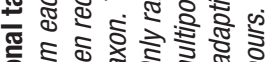

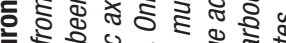

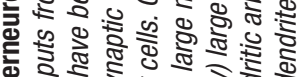

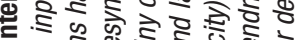

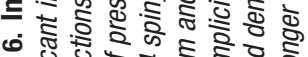

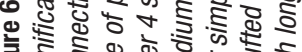

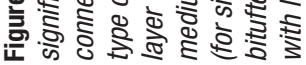




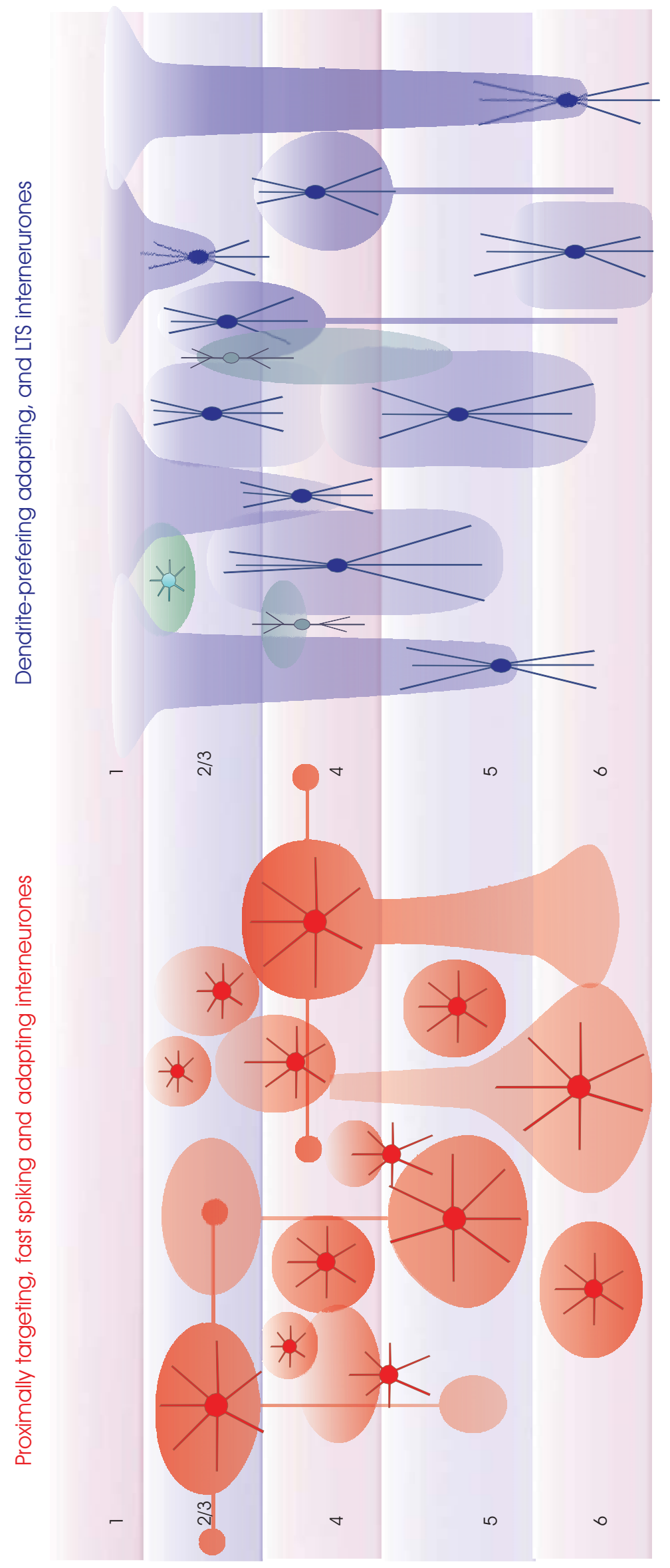

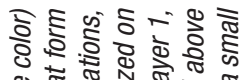
ڤ

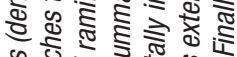

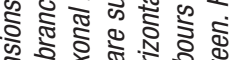

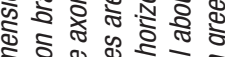
हิ ว

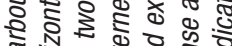

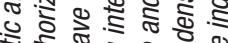

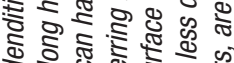
ब क क ळ

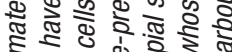

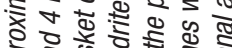
离

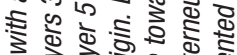

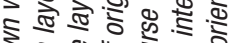

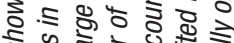
क 心 సั कू 닐 ऊ 후웡

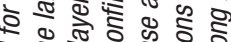

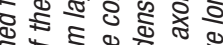
ڤิ ป ڤ

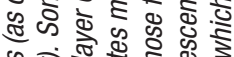

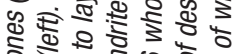

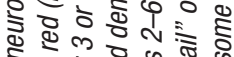

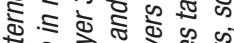

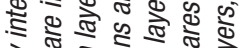

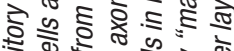

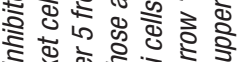

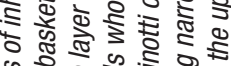

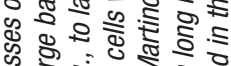
क्ष

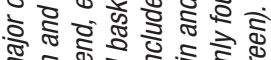

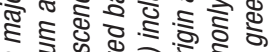

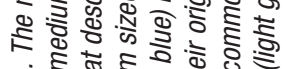

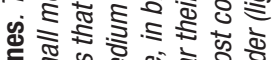

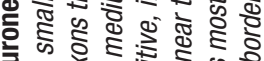

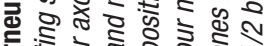
농

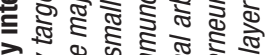
현

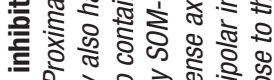

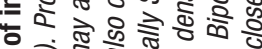

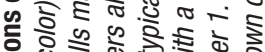

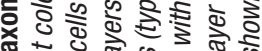

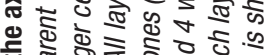

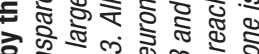

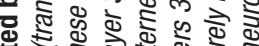
का 농

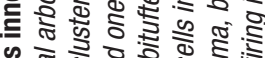

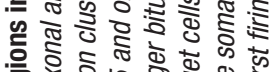

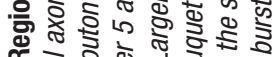

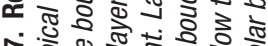

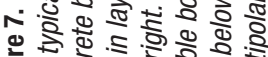

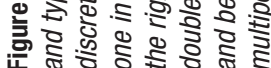


( $\mathrm{N}$-methyl-d-aspartate) receptor-mediated component. However, hits rates vary considerably and there are some differences in average amplitude and time course when connections in different layers are compared. The largest EPSPs recorded have been those resulting from connections between very closely neighboring layer 5 pyramidal cells, while the outputs of layer 6 CT cells are typically the smallest intralaminar pyramid-pyramid EPSPS at low firing frequencies. Intralaminar pyramid-pyramid connections in layer 3 produce EPSPs that are on average smaller than those in layer 5, but larger than those in layer 4. The highest "hit rate" reported is for the descending connections from layer 3 pyramidal cells to large layer 5 , IB pyramids which can be higher than 1:2 if the two apical dendrites are adjacent. In contrast the probability of a layer 3 pyramid innervating a small adapting pyramid in layer 5 is very low. Among the lowest hit rates reported are those for connections associated with a "back projection" from layer 3 to layer 4 and from layer 5 to layer 3 and for synapses made by layer 6 CT cells with other pyramidal cells.

It is here that the differences between the hit rates found with paired recordings and those predicted from bouton and target densities (Binzegger et al., 2004) differ most strikingly and demonstrate most clearly the level of selectivity in the connections made by spiny excitatory cells. A random connection model predicts as powerful an input to layer 3 pyramids from layer 5 pyramids with axon ascending to layer 3 as from layer 4 spiny cells with ascending axons. Similarly, it predicts that an input to the ascending dendrites of layer 4 pyramidal cells from layer 3 pyramidal cells is as strong as the input within layer 4 from other layer 4 spiny cells with ascending axons.

In rat frontal cortex, pyramidal cells that project only to the striatum were frequently reciprocally connected via inputs to basal dendrites. They also innervated pyramidal cells that projected to both striatum and pons via both basal and apical dendritic contacts, but connections in the reverse direction from cells projecting to the pons (and striatum) to cells projecting only to the striatum were rare (Morishima and Kawaguchi, 2006).

There is also a level of specificity in the regions of the postsynaptic neurone targeted by presynaptic neurones of a given class. For example, the connections from layer 4 spiny cells to layer 4 and layer 3 pyramids preferentially target the basal dendrites (Bannister and Thomson, 2007; Lubke et al., 2003). In contrast, the random connection models predicts that layer 4 pyramidal cells will receive significant input to their apical dendrites in layer 3 from other layer 4 spiny cells. Dye-filling of synaptically connected cell pairs reveals very few such connections. In layer 5 particularly, there may also be a gradual shift from proximal contacts onto basal dendrites with very closely neighboring cell pairs, through contacts onto apical oblique dendrites to more distal contacts onto apical dendrites when the two connected cells are separated further laterally.

It is, of course, possible that connections of the "back projection" type, or onto different parts of the dendritic tree, occur more frequently than these data suggest when cells are separated further laterally. Not only have the majority of paired recording experiments studied relatively closely neighboring pairs of neurones, they have been performed in slices in which many longer distance axons are cut. Interpretation of the data included in the tables should keep this in mind.

It has also been a fairly consistent finding that when one axon makes multiple synapses onto the dendrites of another cell, these are at similar locations. This is the case even (as is the common finding) when several axonal branches and different dendrites are involved in the connection. Events recorded from different connections can differ considerably in shape and in synapse location (Markram et al., 1998), the more distally located the synapses, the broader the resultant EPSPs recorded at the soma. The EPSPs resulting from a single connection do not however vary in this way. When the shapes of many EPSPs from the same connection are compared, they are similar in shape, despite the considerable fluctuations in amplitude that result from the stochastic behavior of synaptic release. This similarity is, of course, dependent upon membrane potential.
When a pyramidal cell is depolarized, large fluctuations in the amplitude and duration of the NMDA receptor mediated component can result in dramatic differences in EPSP shape from event to event (Thomson and West, 1993; Thomson et al., 1993).

\section{EXCITATORY INPUTS ONTO INTERNEURONES}

The tables summarise the hit rates, amplitudes and time course for the pyramid to interneurone EPSPs recorded with dual sharp and dual wholecell recordings. For some of the earlier studies and many of those that used dual sharp electrode recordings, the postsynaptic interneurones included a number of different classes and the hit rates given may include a range of target types. Studies that have used IR-DIC to target whole-cell recordings to interneurones with a soma of a particular size and shape have narrowed these limits. Subsequent dye-filling and reconstruction in some studies does, however, demonstrate that a range of morphological subclasses may be included, so that subclassification still relies upon additional information, such as axonal and dendritic arborization patterns, immunofluorescent or RT-PCR identification of specific markers. More recently GFP-labeled interneurones in genetically modified mice have allowed some specific classes to be targeted using fluorescence microscopy in the living slice. In the tables and legends we attempt to indicate both the type(s) of interneurone included in each population listed and the methods used to identify them. For example, where the fully reconstructed neurone can be classified according to its structure (following biocytin-labeling), where the expression or absence of one or more selective markers has been demonstrated (by immunofluorescence or RT-PCR), where classification relies upon soma shape (large, small, round, or fusiform) and firing characteristics (e.g., fast spiking (FS) or LTS and so on. In addition, several studies have pooled data obtained for a similar class of postsynaptic interneurone across different layers.

Intralaminar connections from spiny excitatory cells to interneurones are frequent and do not appear to show striking preference for any particular interneuronal class. They exhibit however, a wide range of properties which are (with the exception of the outputs of layer 6 CT cells) shared by the inputs to each class from other layers. The EPSPs activated in PV-immunopositive interneurones with narrow action potentials and high maximum firing rates (e.g., PV basket cells) are very brief and typically strongly depressing. Multipolar interneurones with moderately fast APs and adapting firing patterns (e.g., CCK basket cells) also typically receive depressing EPSPs of intermediate duration, while the EPSPs recorded in bitufted interneurones with broad APs and an adapting or LTS firing pattern are strongly facilitating and sometimes augmenting. This latter group of typically SOM-immunopositive interneurones, includes both subclasses of Martinotti-like cells, double bouquet cells, and other bitufted cells. Bipolar interneurones that have been found to elicit IPSPs in pyramids and possibly, therefore, correspond with those that do not contain CR or ChAT, typically receive broad depressing EPSPs, while ChAT-immunopositive bipolar cells are reported to receive facilitating inputs (von Engelhardt et al., 2007).

\section{SYNAPTIC CONNECTIONS BETWEEN INHIBITORY INTERNEURONES}

Relatively fewer studies have investigated these connections in detail. We do not, therefore, present a table or discuss them in detail. Studies of adult neocortex indicate that connections between interneurones of all classes are dense and involve quite disparate classes and interneurones in different layers. The time course of these events reflects the properties of both interneurones, those that generate narrow spikes receiving and delivering the fastest IPSPs. For discussion of such connections in juvenile rats see (Gupta et al., 2000). 


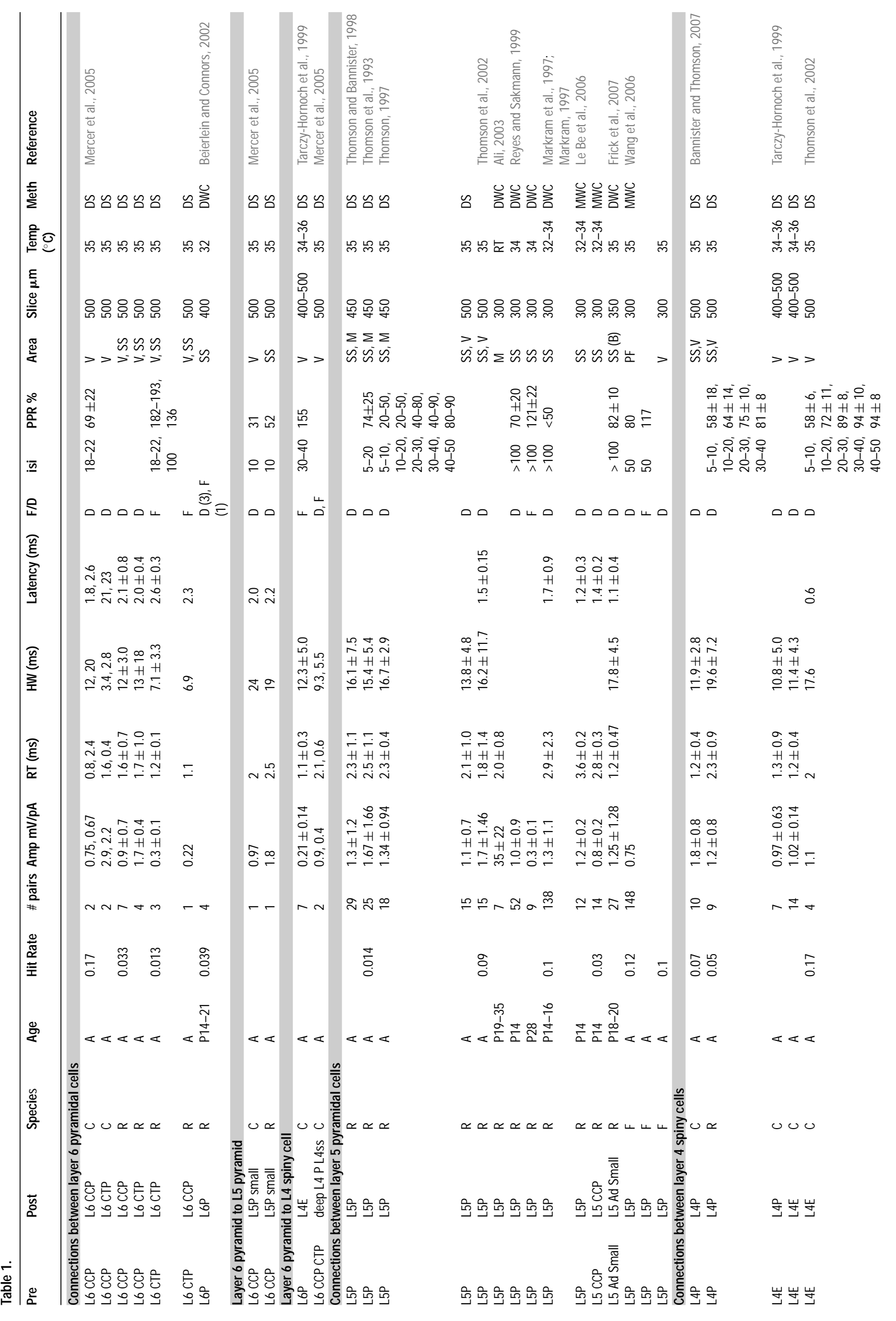




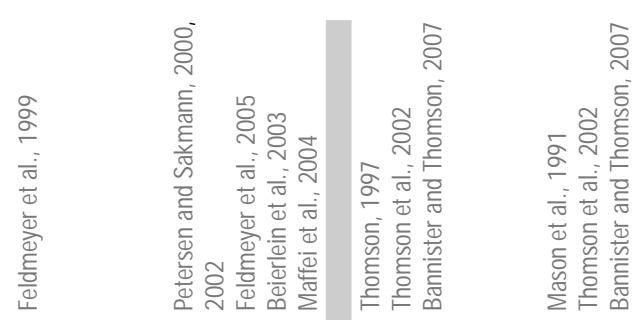

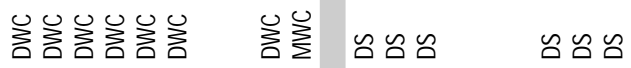

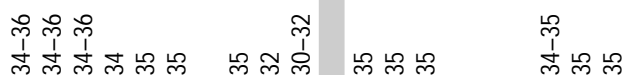

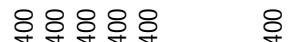

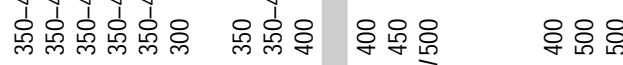

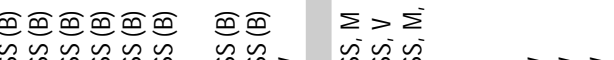

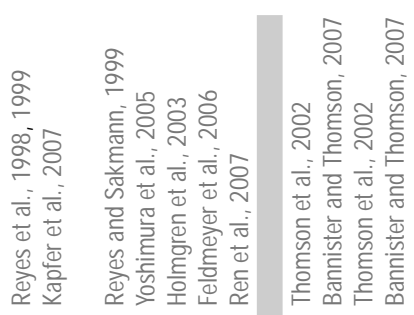

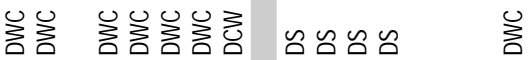

स

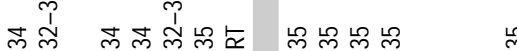

\& 8

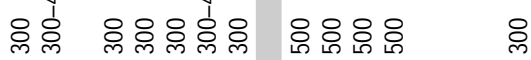

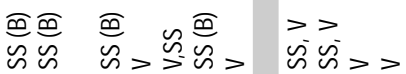

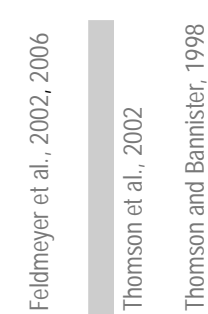

888

$\underline{m} \stackrel{m}{m}$

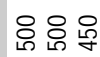

$>$ is vi

n

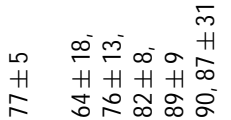

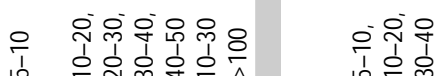

० ᄂ \&

$\triangle \circ \circ$

$\circ$

$\triangle \quad 0$

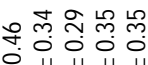

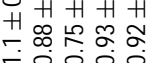

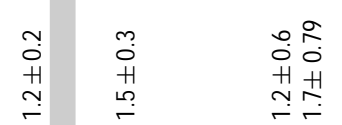

กิำำ

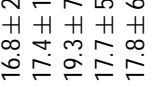

เก่ ย ขั

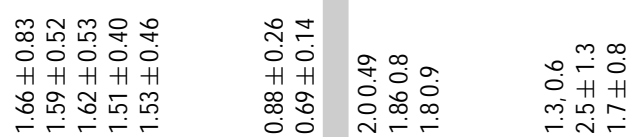

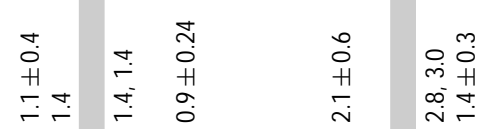

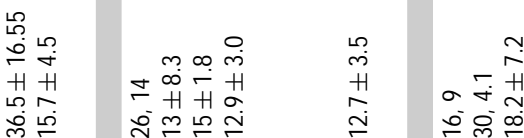

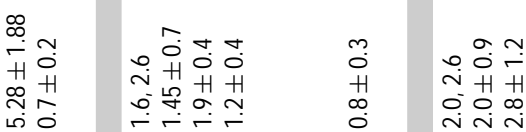

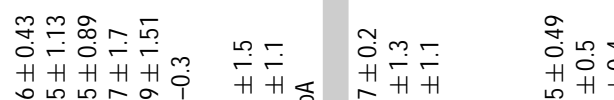

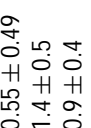

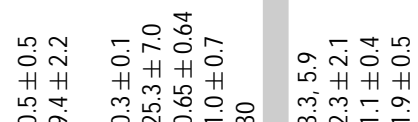

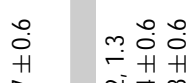

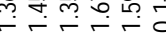

$\infty \infty m$

J $\quad$ त t

8

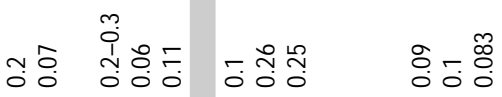

ทำำำำ 꾸

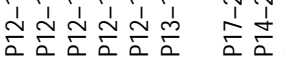

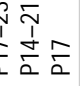

$\varangle \varangle \varangle \quad \varangle \varangle \varangle$

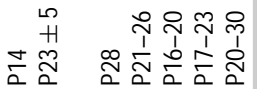

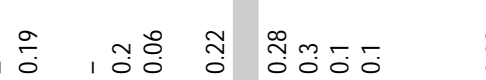

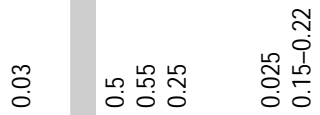

N

$\varangle \varangle \varangle \quad \varangle \quad \frac{m}{d}$

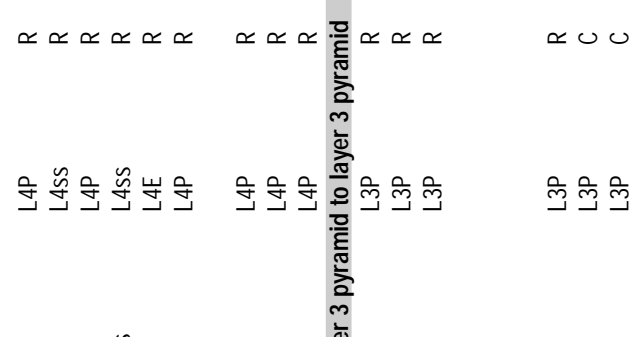

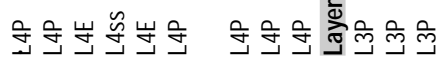

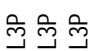
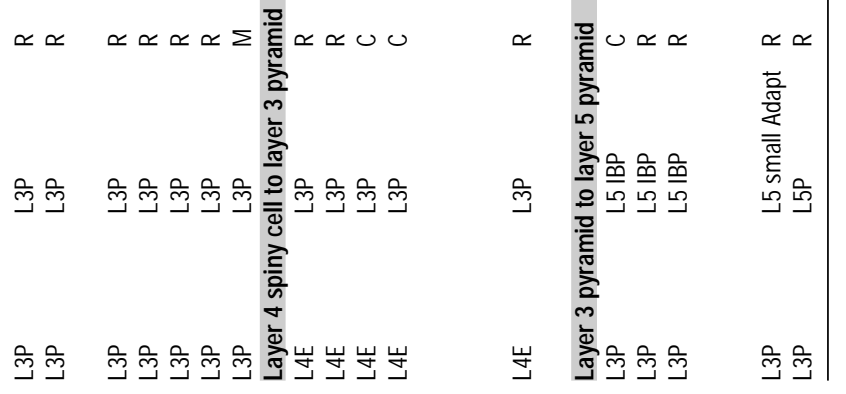


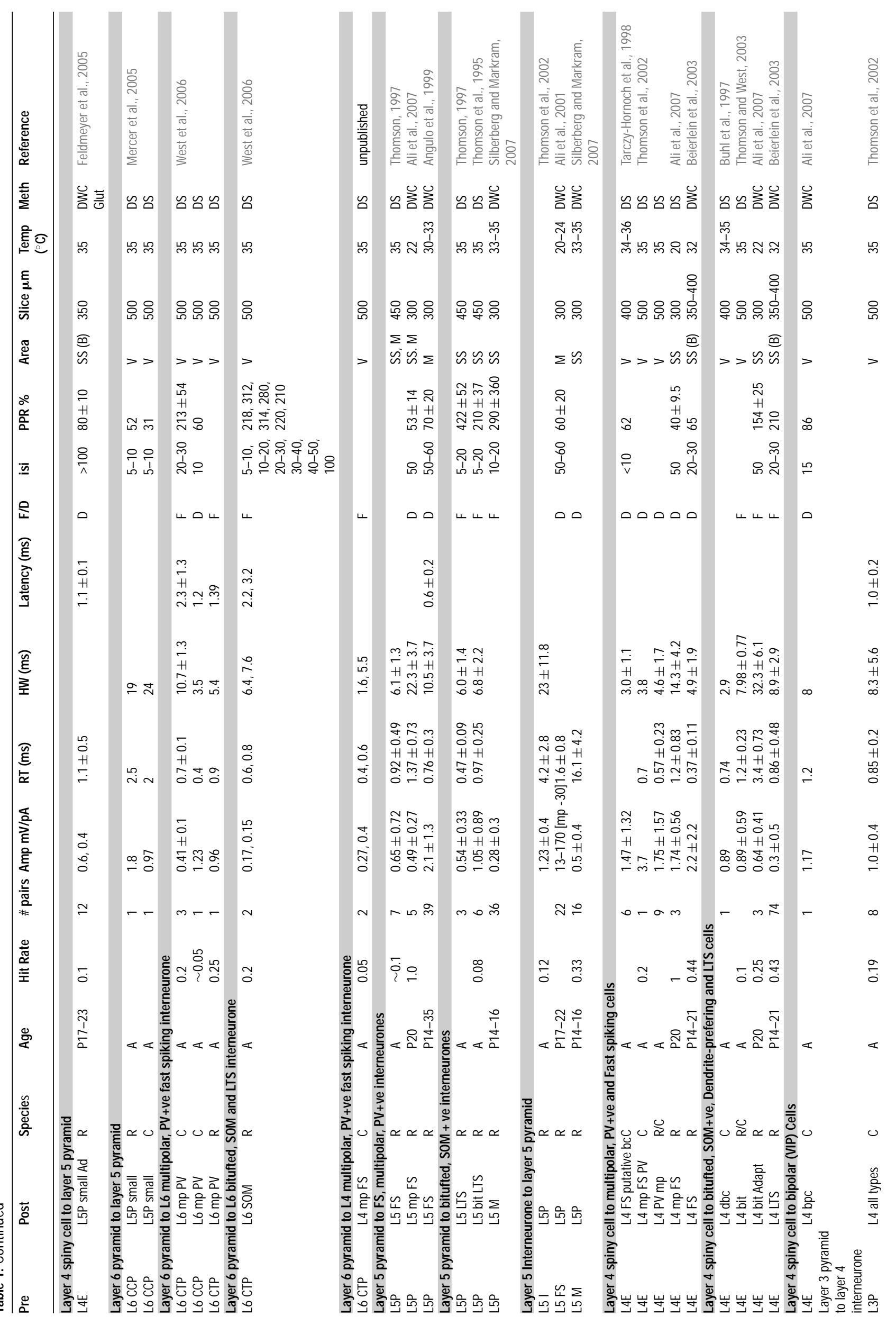




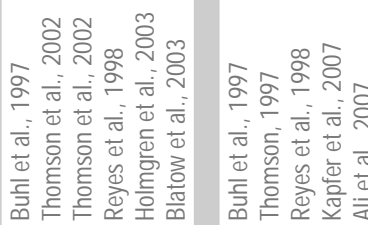

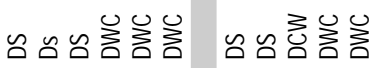
m 夰 足 夰 N

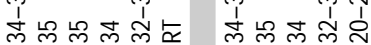

\section{\&}

\& 8 \& 8 \& 8 \& 8 品 \&

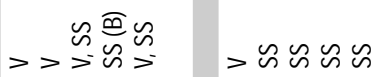

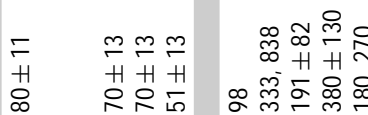

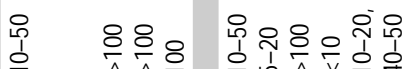

र र

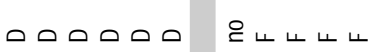

ํ. m.

苗

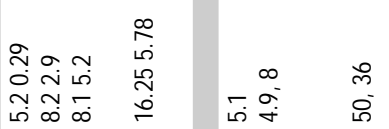

突.

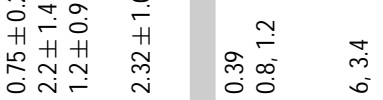

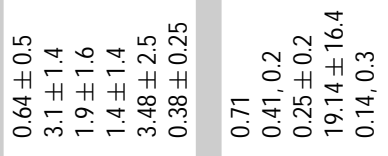

$m \in A \quad 4 \quad \pi \quad n$

4⿻ำ

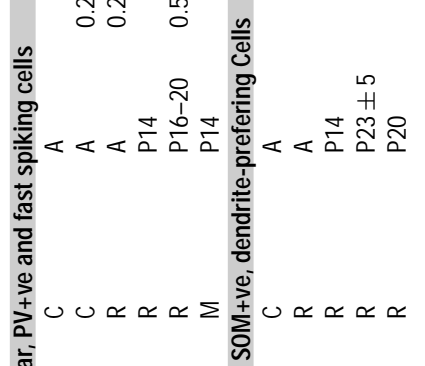

है

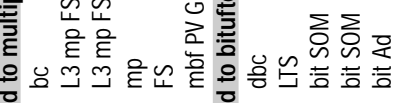

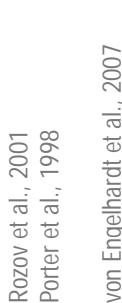

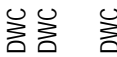

तु

$8 \begin{array}{lll}8 & 8 \\ m & 0 & 0\end{array}$

ทे $\Sigma$

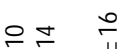

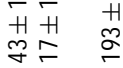

$8 \begin{array}{ll}8 & 8 \\ 0 & 0\end{array}$

离

0
0
0
0
0
0
0

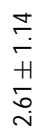

0
in
0
0
0
0

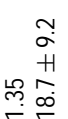

$\stackrel{\infty}{\rightarrow} \overrightarrow{7} \stackrel{\eta}{9}$

贾弯

웅

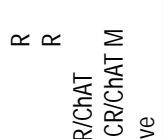

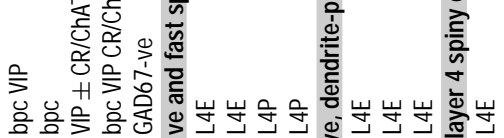

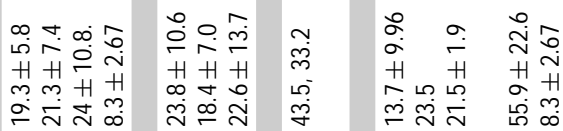

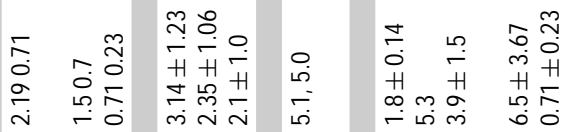

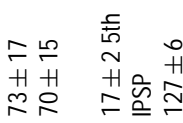

88

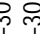

우

ᄋ

DOD

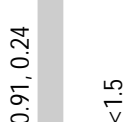

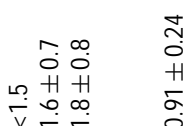

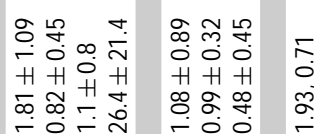

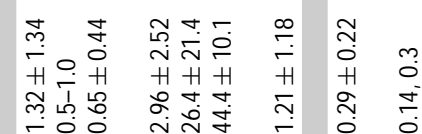

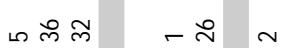

nผ คี

$m$
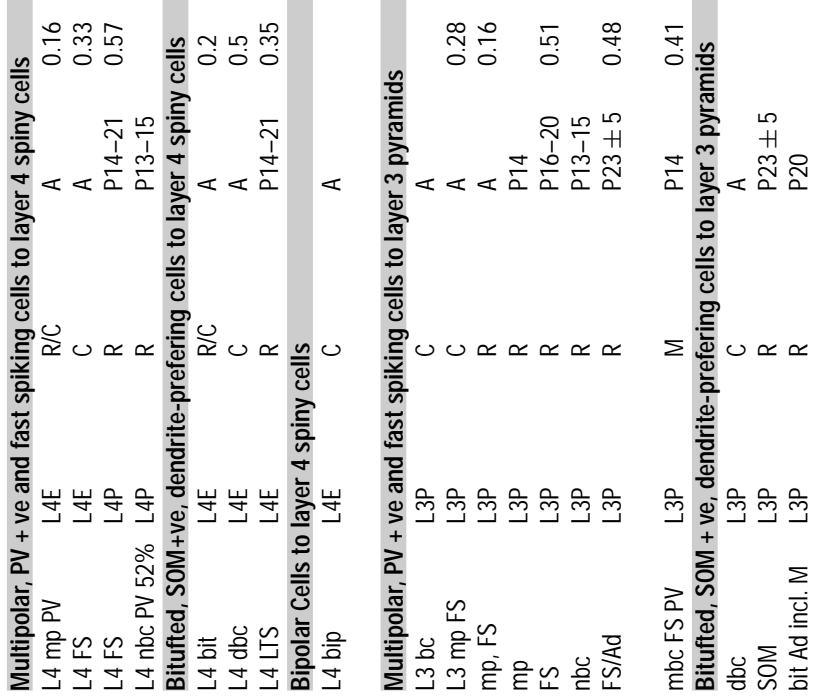

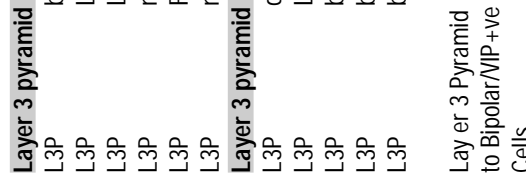




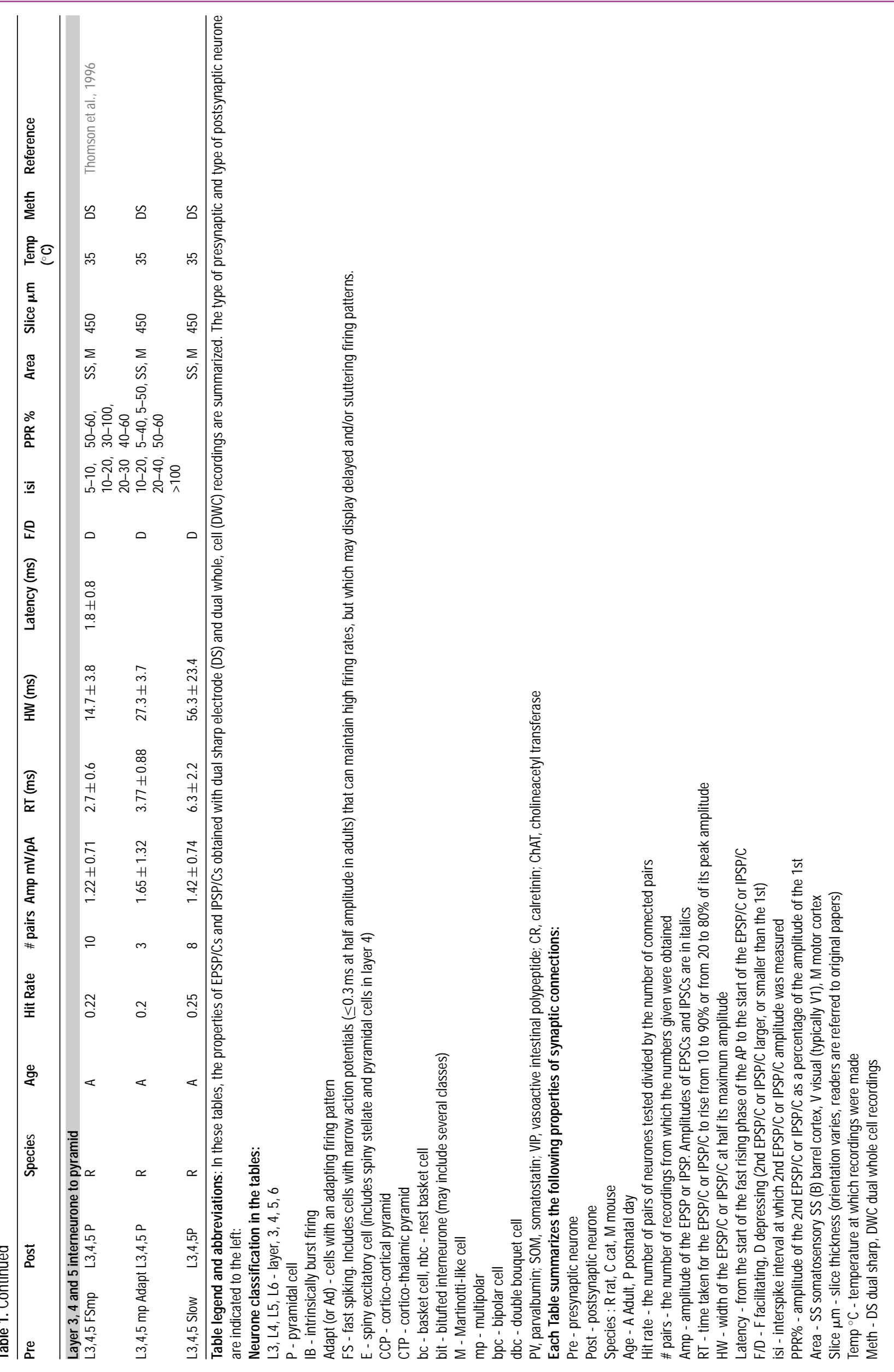




\section{SYNAPTIC DYNAMICS}

Paired pulse and frequency dependent depression appear to involve several different mechanisms, all of which result in a decrease in the probability of release $(p)$ and/or the number of synapses available for release (when $p$ is very low functional $n$ may fall). Facilitation, augmentation and potentiation, on the other hand, enhance the probability of release during repetitive activity. Some of these mechanisms, such as those resulting in release site refractoriness, or the decrease in the readily available pool of transmitter on continued repetitive firing, as well as facilitation and post-tetanic potentiation, appear to be expressed at all synaptic connections studied to date, albeit more or less obscured by the effects of other mechanisms under different circumstances. Others, such as augmentation and release independent depression appear to be more selectively expressed (for review Thomson, 2000). The several "depressing" mechanisms combine to limit the output of most pyramid-pyramid connections, while facilitation and potentiation enhance release under appropriate circumstances. Whether a connection is dominated by depression or facilitation when EPSPs are elicited by short trains of presynaptic spikes after a period of rest, depends upon the low frequency release probability. At connections with a low $p$, release-dependent depression is minimal at low frequencies and typically, facilitation dominates. At connections with a high $p$ release-dependent depression dominates and EPSPS depress.

We do not attempt here to discuss the complexities of these mechanisms or the evidence for their differential expression at different classes of synapse. The tables simply provide paired pulse ratios and, where these have been studied, the time constants for the decay of depression or facilitation. To date, detailed comparisons of the time course of these mechanisms between different age groups have not been attempted. As discussed above, few studies of juvenile synapses have investigated the time course in detail, particularly the events occurring at very brief interspike intervals. The paired pulse ratios do, however, indicate that depression and facilitation at juvenile connections is still powerful at intervals at which these phenomena have declined considerably in the adult. For example, in studies of adult rat and cat pyramid-pyramid connections, the time constants for the decay of depression were relatively brief (from 4.4 to $22 \mathrm{~ms}$, Bannister and Thomson, 2007; $12.4 \pm 8.1 \mathrm{~ms}$, Thomson and West, 2003). However, single exponential fits to mean 2nd EPSP amplitudes plotted against interval predicted a $10-20 \%$ residual depression at infinity, indicating the existence of a second, more slowly decaying component (thought to be due to depletion of the immediately releasable pool). In rats at P13-15, however, a single time constant for depression of $813 \pm 240 \mathrm{~ms}$ for pairs of large tufted layer 5 pyramidal cells, and $399 \pm 295 \mathrm{~ms}$ for facilitating inputs onto bitufted interneurones was obtained from fits of a model to experimental data (Markram et al., 1998). Whether this much longer value represents a slower recovery from the same mechanism, or results from measurements obtained when the early component has declined and the later component dominates remains to be determined. Although extremely variable, the time constants for decay of facilitation were also, on average, longer in the younger animals $(1797 \pm 1247 \mathrm{~ms})$ than in adults $(<20 \mathrm{~ms})$ and closer to the time course of decay of augmentation and potentiation in mature preparations.

\section{BINOMIAL PARAMETERS FOR NEOCORTICAL EPSPS}

In a recent study in which paired recording data were fit by simple and complex binomial models, significant differences were found between the mean quantal amplitudes for pyramid-pyramid EPSPs in different layers. In the adult rat, estimates of quantal amplitude for layer 3 and layer 5 pyramid-pyramid connections were larger and for layer 4 connections were smaller than for connections in layer 6 . Thus, although few studies have demonstrated significant differences in the average amplitudes of EPSPs in different layers, because of the wide ranges often observed, the way in which they achieve the same average amplitude varies. In layer 4 it appears that a larger number of smaller quanta with a higher release probability result in EPSPs of similar average amplitude to those resulting from a smaller number of larger quanta in layer 3 . In addition, when excitatory connections onto interneurones and pyramids were compared, the estimated quantal amplitudes for those onto interneurones were larger than for inputs onto pyramidal cells (Bremaud et al., 2007).

\section{CONFLICT OF INTEREST STATEMENT}

The research was conducted in the absence of any commercial or financial relationships that could be construed as a potential conflict of interest.

\section{ACKNOWLEDGEMENTS}

The Medical Research Council UK, Wellcome Trust, Novartis Pharma (Basel), and the EU FP6 FACETS project funded the work from this group that is cited here.

\section{REFERENCES}

Aaron, G., and Yuste, R. (2006) Reverse optical probing (ROPING) of neocortical circuits. Synapse. 60, 437-440.

Ahmed, B., Anderson, J. C., and Douglas, R. J, Martin, K. A. C., and Nelson, J. C. (1994) Polyneuronal innervation of spiny stellate neurons in cat visual cortex. J. Comp. Neurol. 341, 39-49.

Ali, A. B. (2003) Involvement of post-synaptic kainate receptors during synaptic transmission between unitary connections in rat neocortex. Eur. J. Neurosci. 17, 23442350.

Ali, A. B., Rossier, J, Staiger, J. F., and Audinat, E. (2001) Kainate receptors regulate unitary IPSCs elicited in pyramidal cells by fast-spiking interneurons in the neocortex. J. Neurosci. 21, 2992-2999.

Ali, A. B, Bannister, A. P., and Thomson, A. M. (2007) Robust correlations between action potential duration and the properties of synaptic connections in layer 4 interneurones in neocortical slices from juvenile rats and adult rat and cat. J. Physiol. 580, 149-169.

Angulo, M. C., Rossier, J., and Audinat, E. (1999) Postsynaptic glutamate receptors and integrative properties of fast-spiking interneurons in the rat neocortex. J. Neurophysiol. 82, 1295-1302.

Arenkiel, B. R., Peca, J., Davison, I. G., Feliciano, C., Deisseroth, K., Augustine, G. J., Ehlers, M. D., and Feng, G. (2007) In vivo light-induced activation of neural circuitry in transgenic mice expressing channelrhodopsin-2. Neuron 54, 205-218.

Bannister, A. P, and Thomson, A. M, (2007) Dynamic Properties of Excitatory Synaptic Connections Involving Layer 4 Pyramidal Cells in Adult Rat and Cat Neocortex. Cereb. Cortex 17, 2190-2203

Beaulieu, C., and Colonnier, M. (1985) A laminar analysis of the number of roundasymmetric and flat-symmetric synapses on spines, dendritic trunks, and cell bodies in area 17 of the cat. J. Comp. Neurol. 231, 180-189.

Beierlein, M., and Connors, B. W. (2002) Short-term dynamics of thalamocortical and intracortical synapses onto layer 6 neurons in neocortex. J. Neurophysiol. 88, 1924-1932.

Beierlein, M., Gibson, J. R., and Connors, B. W. (2003) Two dynamically distinct inhibitory networks in layer 4 of the neocortex. J. Neurophysiol. 90, 2987-3000.

Benshalom, G., and White, EL. (1986) Quantification of thalamocortical synapses with spiny stellate neurons in layer IV of mouse somatosensory cortex. J. Comp. Neurol. 253, 303-314

Binzegger, T., Douglas, R. J., and Martin, K. A. (2004) A quantitative map of the circuit of cat primary visual cortex. J. Neurosci. 24, 8441-8453.

Blatow, M., Rozov, A., Katona, I., Hormuzdi, S. G., Meyer, A. H., Whittington, M. A., Caputi, A., and Monyer, H. (2003) A novel network of multipolar bursting interneurons generates theta frequency oscillations in neocortex. Neuron 38, 805-817.

Blatow, M., Caputi, A., and Monyer, H. (2005) Molecular diversity of neocortical GABAergic interneurones. J. Physiol. 562, 99-105.

Borg-Graham LJ, Monier C, Fregnac Y. (1998) Visual input evokes transient and strong shunting inhibition in visual cortical neurons. Nature. 393(6683):369-373.

Bremaud, A., West D. C., and Thomson, A. M. (2007) Binomial parameters differ across neocortical layers and with different classes of connections in adult rat and cat neocortex. PNAS 104(35):14134-9.

Buhl, E. H, Tamas, G., Szilagyi, T., Stricker, C., Paulsen, O., and Somogyi, P. (1997) Effect, number and location of synapses made by single pyramidal cells onto aspiny interneurones of cat visual cortex. J. Physiol. 500, 689-713.

Burkhalter, A. (1989) Intrinsic connections of rat primary visual cortex: laminar organization of axonal projections. J. Comp. Neurol. 279, 171-186.

Callaway, E. M., and Katz, L. C. (1993) Photostimulation using caged glutamate reveals functional circuitry in living brain slices. Proc. Natl. Acad. Sci. USA 90, 7661-7665.

Cauli, B., Tong, X. K., Rancillac, A., Serluca, N., Lambolez, B., Rossier, J., and Hamel, E. (2004) Cortical GABA interneurons in neurovascular coupling: relays for subcortical vasoactive pathways. J. Neurosci. 24, 8940-8949.

Civillico, E. F., and Contreras, D. (2005) Comparison of responses to electrical stimulation and whisker deflection using two different voltage-sensitive dyes in mouse barrel cortex in vivo. J. Membr. Biol. 208, 171-182.

Civillico, E. F, and Contreras, D. (2006) Integration of evoked responses in supragranular cortex studied with optical recordings in vivo. J. Neurophysiol. 96, 336-351. 
Condé, F., Lund, J. S., Jacobowitz, D. M., Baimbridge, K. G., and Lewis, D. A. (1994) Local circuit neurons immunoreactive for calretinin, calbindin D-28k or parvalbumin in monkey prefronatal cortex: Distribution and morphology. J. Comp. Neurol. 341, 95-116.

Connors, B. W., Gutnick, M. J., and Prince, D. A. (1982) Electrophysiological properties of neocortical neurons in vitro. J. Neurophysiol. 48, 1302-1320.

Contreras, D., and Llinas, R. (2001) Voltage-sensitive dye imaging of neocortical spatiotemporal dynamics to afferent activation frequency. J. Neurosci. 21, 9403-9413.

Del Rio, M. R., and DeFelipe, J. (1997) Double bouquet cell axons in the human tempora neocortex: relationship to bundles of myelinated axons and colocalization of calretinin and calbindin D-28k immunoreactivities. J. Chem. Neuroanat. 13, 243-251.

Deuchars, J., West, D. C., and Thomson, A. M. (1994) Relationships between morphology and physiology of pyramid-pyramid single axon connections in rat neocortex in vitro. J. Physiol. 478, 423-435.

Elhanany, E., and White, E. L. (1990) Intrinsic circuitry: synapses involving the local axon collaterals of corticocortical projection neurons in the mouse primary somatosensory cortex. J. Comp. Neurol. 291, 43-54.

Fairén, A, De Felipe, J., and Regidor, J. (1984) Nonpyramidal neurons. In Cerebral Cortex Vol. 1 A. Peters, E. G. Jones, (Eds.), New York: Plenum Press, pp. 201-253.

Feldman, M. L., and Peters, A. (1978) The forms of non-pyramidal cells in the visual cortex of the rat. J. Comp. Neurol. 179, 761-794.

Feldmeyer, D., Egger, V., Lubke, J., and Sakmann, B. (1999) Reliable synaptic connections between pairs of excitatory layer 4 neurones within a single 'barrel' of developing rat somatosensory cortex. J. Physiol. 521, 169-190.

Feldmeyer, D., Lubke, J., Silver, R. A., and Sakmann, B. (2002) Synaptic connections between layer 4 spiny neurone-layer $2 / 3$ pyramidal cell pairs in juvenile rat barre cortex: physiology and anatomy of interlaminar signalling within a cortical column. J. Physiol. 538, 803-822.

Feldmeyer, D., Roth, A., and Sakmann, B. (2005) Monosynaptic connections between pairs of spiny stellate cells in layer 4 and pyramidal cells in layer $5 \mathrm{~A}$ indicate that lemniscal and paralemniscal afferent pathways converge in the infragranular somatosensory cortex. J. Neurosci. 25, 3423-3431.

Freund, T. F., Martin, K. A., Somogyi, P., and Whitteridge, D. (1985) Innervation of cat visual areas 17 and 18 by physiologically identified X- and Y- type thalamic afferents. II. Identification of postsynaptic targets by GABA immunocytochemistry and Golg impregnation. J. Comp. Neurol. 242, 275-291.

Freund, T. F., Magloczky, Z., Soltesz, I., and Somogyi, P. (1986) Synaptic connections, axonal and dendritic patterns of neurons immunoreactive for cholecystokinin in the visual cortex of the cat. Neuroscience. 19, 1133-1159.

Frick, A., Feldmeyer D., Helmstaedter M., and Sakmann B. (2007) Monosynaptic Connections between Pairs of L5A Pyramidal Neurons in Columns of Juvenile Rat Somatosensory Cortex. Cereb. Cortex. Epub:4 Jun 2007.

Fujita, I., and Fujita, T. (1996) Intrinsic connections in the macaque inferior tempora cortex J. Comp. Neurol. 368, 467-486.

Gabbott, P. L. A., Dickie, B. G. M., Vaid, R. R., Headlam, A. J. N., and Bacon. S. J. (1997) Local-circuit neurones in the medial prefrontal cortex (areas 25, 32, and 24b) in the rat: morphology and quantitative distribution. J. Comp. Neurol. 377, 465-499.

Gilbert, C. D. (1983) Microcircuitry of the visual cortex. Annu. Rev. Neurosci. 6, 217-247.

Gilbert, C. D., and Wiesel, T. N. (1983) Clustered intrinsic connections in cat visual cortex J. Neurosci. 3, 1116-1133.

Gulyas, A. I., Hajos, N., and Freund, T. F. (1996) Interneurons containing calretinin are specialized to control other interneurons in the rat hippocampus. J. Neurosci. 16 $3397-3411$.

Gupta, A., Wang, Y., and Markram, H. (2000) Organizing principles for a diversity of GABAergic interneurons and synapses in the neocortex. Science 287, 273-278.

Hajos, F., Staiger, J. F., Halasy, K., Freund, T. F., and Zilles, K. (1997) Geniculo cortical afferents form synaptic contacts with vasoactive intestinal polypeptide (VIP) immunoreactive neurons of the rat visual cortex. Neurosci. Lett. 228, 179-182.

Hallman, L. E., Schofield, B. R., and Lin, C. S. (1988) Dendritic morphology and axon collaterals of corticotectal, corticopontine, and callosal neurons in layer V of primary visual cortex of the hooded rat. J. Comp. Neurol. 272, 149-160.

Han, X., and Boyden, E. S. (2007) Multiple-color optical activation, silencing, and desynchronization of neural activity, with single-spike temporal resolution. PLOS ONE. 21 2:e299.

Hersch, S. M., and White, E. L. (1981) Quantification of synapses formed with apica dendrites of Golgi-impregnated pyramidal cells: variability in thalamocortical inputs but consistency in the ratios of asymmetrical to symmetrical synapses. Neuroscience 6, 1043-1051.

Hersch, S. M., and White E. L. (1981) Thalamocortical synapses involving identified neurons in mouse primary somatosensory cortex: a terminal degeneration and golgi/EM study. J. Comp. Neurol. 195, 253-263.

Hirsch, J. A., Gallagher, C. A., Alonso, J.- M., and Martinez, L.M (1998) Ascending projections of simple and complex cells in layer 6 of the cat striate cortex. J. Neurosci. 18, 8086-8094.

Holmgren, C., Harkany, T., Svennenfors, B., and Zilberter, Y. (2003) Pyramidal cell communication within local networks in layer $2 / 3$ of rat neocortex. J. Physiol. 551 139-153.

Howard, A., Tamás, G., and Soltesz, I. (2005) Lighting the chandelier: new vistas for axo-axonic cells. Trends Neurosci. 28, 310-316.

Hubener, M., Schwarz, C., and Bolz, J. (1990) Morphological types of projection neurons in layer 5 of cat visual cortex. J. Comp. Neurol. 301, 655-674.

Hughes, D. I., Bannister, A. P., Pawelzik, H., and Thomson, A. M. (2000) Double immuno-fluorescence, peroxidase labeling and ultrastructural analysis of interneu- rones following prolonged electrophysiological recordings in vitro. J. Neurosci. Meth. $101,107-116$

Jones, E. G. (1984) Neurogliaform or spiderweb cells. In Cerebral cortex, Vol. 1, Cellular components of the cerebral cortex, A. Peters, E. G. Jones, (eds.), New York: Plenum Press, pp. 409-418.

Jones, E. G. (1998) Viewpoint: the core and matrix of thalamic organization. Neuroscience $85,331-345$.

Kampa, B. M., Letzkus, J. J., and Stuart, G. J. (2006) Cortical feed-forward networks for binding different streams of sensory information Nat Neurosci. 9, 1472-1473.

Kapfer, C., Glickfeld, L. L., Atallah, B. V., and Scanziani, M. (2007) Supralinear increase of recurrent inhibition during sparse activity in the somatosensory cortex. Nat. Neurosci. $10,743-753$.

Kasper, E. M., Larkman, A. U., Lubke, J., and Blakemore, C. (1994) Pyramidal neurons in layer 5 of the rat visual cortex. I. Correlation among cell morphology, intrinsic electrophysiological properties, and axon targets. J. Comp. Neurol. 339 , 459-474.

Katona, I., Sperlagh, B., Sik, A., Kafalvi, A., Vizi, E. S., Mackie, K., and Freund, TF. (1999) Presynaptically located CB1 cannabinoid receptors regulate GABA release from axon terminals of specific hippocampal interneurons. J Neurosci. 19:4544-4558.

Katz, L. C, (1987) Local circuitry of identified projection neurons in cat visual cortex brain slices. J. Neurosci. 7, 1223-1249.

Kawaguchi, Y. (1993) Groupings of nonpyramidal and pyramidal cells with specific physiological and morphological characteristics in rat frontal cortex. J. Neurophysiol. 69 , 416-431.

Kawaguchi, Y., and Kubota, Y. (1993) Correlation of physiological subgroupings of nonpyramidal cells with parvalbumin- and calbindinD28k-immunoreactive neurons in layer $\mathrm{V}$ of rat frontal cortex. J. Neurophysiol. 70, 387-396.

Kawaguchi, Y., and Kubota, Y. (1997) GABAergic cell subtypes and their synaptic connections in rat frontal cortex. Cereb. Cortex 7, 476-486.

Kawaguchi, Y., and Kubota, Y. (1998) Neurochemical features and synaptic connections of large physiologically-identified GABAergic cells in the rat frontal cortex. Neuroscience 85, 677-701.

Kirov, S. A., Sorra, K. E., and Harris, K. M. (1999) Slices have more synapses than perfusion-fixed hippocampus from both young and mature rats. J. Neurosci. 19 2876-2886

Kisvarday, Z. F., and Eysel, U. T. (1993) Functional and structural topography of horizontal inhibitory connections in cat visual cortex. Eur. J. Neurosci. 5, 1558-1572.

Kisvarday, Z. F., Cowey, A., and Somogyi, P. (1986) Synaptic relationships of a type of GABA- immunoreactive neuron (clutch cell), spiny stellate cells and lateral geniculate nucleus afferents in layer IVC of the monkey striate cortex. Neuroscience 19 $741-761$

Kisvárday, Z. F., Martin, K. A. C., Freund, T. F., Maglóczky, Zs., Whitteridge, D., and Somogyi, P. (1986) Synaptic targets of HRP-filled layer III pyramidal cells in the cat striate cortex. Expl. Brain Res. 64, 541-552.

Kisvárday, Z. F., Gulyás, A., Beroukas, D., North, J. B., Chubb, I. W., and Somogyi, P. (1990) Synapses, axonal and dendritic patterns of GABAimmunoreactive neurons in human cerebral cortex. Brain 113, 793-812.

Kritzer, M. F., and Goldman-Rakic, P. S. (1995) Intrinsic circuit organization of the majo layers and sublayers of the dorsolateral prefontal cortex in the rhesus monkey. $J$. Comp. Neurol. 359, 131-143.

Kubota, Y., Hatada, S., Kondo, S., Karube, F., and Kawaguchi, Y. (2007) Neocortical inhibitory terminals innervate dendritic spines targeted by thalamococrtical afferents. J. Neurosci. 27, 1139-1150.

Le Be, J. V., and Markram, H. (2006) Spontaneous and evoked synaptic rewiring in the neonatal neocortex. Proc. Natl. Acad. Sci. USA 103, 13214-13219.

Le, Be J. V., Silberberg, G., Wang, Y., and Markram, H. (2006) Morphological, Electrophysological, and Synaptic Properties of Corticocallosal Pyramidal Cells in the Neonata Rat Neocortex. Cereb Cortex Epub:23 Nov 2006.

Levitt, J. B., Lewis, D. A., Yoshioka, T., and Lund, J. S. (1993) Topography of pyramida neuron intrinsic connections in macaque monkey prefrontal cortex (areas 9 and 46). J. Comp. Neurol. 338, 360-376.

Levitt, J. B., Yoshioka, T., and Lund, J. S. (1994) Intrinsic cortical connections in macaque visual area V2: Evidence for interaction between different functional streams. J. Comp. Neurol. 342, 551-570.

Lewis, D. A., and Lund, J. S. (1990) Heterogeneity of chandelier neurons in monkey neocortex: corticotropin-releasing factor- and parvalbumin-immunoreactive populations. J. Comp. Neurol. 293, 599-615.

Lorente de Nó, R. (1922) La corteza cerebral del raton Trab. Lab. Invest. Biol. Madrid. 20 $41-78$.

Lubke. J., Roth, A., Feldmeyer, D., and Sakmann, B. (2003) Morphometric analysis of the columnar innervation domain of neurons connecting layer 4 and layer $2 / 3$ of juvenile rat barrel cortex. Cereb. Cortex. 13, 1051-1063.

Lund, J. S. (1973) Organization of neurons in the visual cortex area 17, of the monkey (Macaca mulatta). J. Comp Neurol. 147, 455-496.

Lund, J. S. (1987) Local circuit neurons of macaque monkey striate cortex: I Neurons of laminae 4C and 5A. J. Comp. Neurol. 159, 305-334.

Lund, J. S. (1987) Local circuit neurons of macaque monkey striate cortex: I. Neurons of laminae 4C and 5A. J. Comp. Neurol. 257, 60-92.

Lund, J. S. (1988) Anatomical organization of Macaque monkey striate visual cortex. Ann. Rev. Neurosci. 11, 253-288.

Lund, J. S., Hawken, M. J., and Parker, A. J. (1988) Local circuit neurons of macaque monkey striate cortex: II. Neurons of laminae 5B and 6. J. Comp. Neurol. 276, 1-29.

40 
Lund, J. S., Yoshioka, T., and Levitt, J. B (1993) Comparison of intrinsic connectivity in different areas of macaque monkey cerebral cortex Cerebral Cortex 3, 148-162.

Ma, Y., Hu, H., Berrebi, A. S., Mathers, P. H., and Agmon, A. (2006) Distinct subtypes of somatostatin- containing neocortical interneurons revealed in transgenic mice. $J$. Neurosci. 26, 5069-5082.

Maffei, A., Nelson, S. B., and Turrigiano, G. G. (2004). Selective reconfiguration of layer 4 visual cortical circuitry by visual deprivation. Nat. Neurosci. 7, 1353-1359.

Markram, H. (1997) A network of tufted layer 5 pyramidal neurons. Cereb. Cortex. 7 , 523-533.

Markram, H., Lubke, J., Frotscher, M., Roth, A., and Sakmann, B (1997) Physiology and anatomy of synaptic connections between thick tufted pyramidal neurones in the developing rat neocortex. J. Physiol. 500, 409-440.

Markram, H., Wang, Y., and Tsodyks, M. (1998) Differential signaling via the same axon of neocortical pyramidal neurons. Proc. Natl. Acad. Sci. USA 95, 5323-5328.

Martinotti, C. (1889) Contributo allo studio della corteccia cerebrale, ed all'origine central dei nervi. Ann. Reniatr. Sci. Affini 1, 314-381.

Mason, A., Nicoll, A., and Stratford, K (1991) Synaptic transmission between individual pyramidal neurons of the rat visual cortex in vitro. J. Neurosci. 11, 72-84.

McGuire, B. A., Hornung, J. P., Gilbert, C. D., and Wiesel, T. N. (1984) Patterns of synaptic input to layer 4 of cat striate cortex. J. Neurosci. 4, 3021-3033.

Mercer, A., West, D. C., Morris, 0. T., Kirchhecker, S., Kerkhoff, J. E., and Thomson, A. M. (2005) Excitatory connections made by presynaptic cortico-cortical pyramidal cells in layer 6 of the neocortex. Cereb. Cortex. 15, 1485-1496.

Monyer, H., and Markram, H. (2004) Interneuron Diversity series: Molecular and genetic tools to study GABAergic interneuron diversity and function. Trends Neurosci. 27 90-97.

Morishima, M., and Kawaguchi, Y. (2006) Recurrent connection patterns of corticostriatal pyramidal cells in frontal cortex. J. Neurosci. 26, 4394-4405

Ohki, K., Chung, S., Ch'ng, Y. H., Kara, P., and Reid, R. C. (2005) Functional imaging with cellular resolution reveals precise micro-architecture in visual cortex. Nature 433 597-603.

Okamoto, K., Nagai, T., Miyawaki, A., and Hayashi, Y. (2004) Rapid and persistent modulation of actin dynamics regulates postsynaptic reorganization underlying bidirectiona plasticity, Nat. Neurosci. 7, 1104-1112.

O'Leary, J. L. (1941) Structure of the area striate in the cat. J. Comp. Neurol. 75, 131-164.

Parnavelas, J. G., Lieberman, A. R., and Webster, K. E. (1977) Organization of neurons in the visual cortex, area 17, of the rat. J. Anat. 124, 305-322.

Peterlin, Z. A., Kozloski, J., Mao, B. Q., Tsiola, A., and Yuste, R. (2000) Optical probing of neuronal circuits with calcium indicators. Proc. Natl. Acad. Sci. USA 97, 3619-3624.

Petersen, C. C., and Sakmann, B. (2000) The excitatory neuronal network of rat layer 4 barrel cortex. J. Neurosci. 20, 7579-7586.

Petreanu, L., Huber, D., Sobczyk, A., and Svoboda, K. (2007) Channelrhodopsin-2assisted circuit mapping of long-range callosal projections. Nat. Neurosci. 10 $663-668$.

Porter, L. L., and White, E. L. (1986) Synaptic connections of callosal projection neurons in the vibrissal region of mouse primary motor cortex: an electron microscopic/horseradish peroxidase study. J. Comp. Neurol. 248, 573-587.

Porter, J. T., Cauli, B., Staiger, J. F., Lambolez, B., Rossier, J., and Audinat, E. (1998) Properties of bipolar VIPergic interneurons and their excitation by pyramidal neurons in the rat neocortex. Eur. J. Neurosci. 10, 3617-3628.

Porter, J. T., Johnson, C. K., and Agmon, A. (2001) Diverse types of interneurons generate thalamus-evoked feedforward inhibition in the mouse barrel cortex. J. Neurosci. 21 2699-2710.

Povysheva, N. V., Zaitsev, A. V., Kroner, S., Krimer, 0. A., Rotaru, D. C., Gonzalez-Burgos, G., Lewis, D. A., and Krimer, L, S. (2007) Electrophysiological differences between neurogliaform cells from monkey and rat prefrontal cortex. J. Neurophysiol. 97, 1030-1039.

Reichova, I., and Sherman, S. M. (2004) Somatosensory corticothalamic projections: distinguishing drivers from modulators. J. Neurophysiol. 92, 2185-2197.

Ren, M., Yoshimura, Y., Takada, N., Horibe, S., and Komatsu, Y. (2007) Specialized inhibitory synaptic actions between nearby neocortical pyramidal neurons. Science 316, 758-761.

Reyes, A., and Sakmann, B (1999) Developmental switch in the short-term modification of unitary EPSPs evoked in layer $2 / 3$ and layer 5 pyramidal neurons of rat neocortex. J. Neurosci. 19, 3827-3835.

Reyes, A., Lujan, R., Rozov, A., Burnashev, N., Somogyi, P., and Sakmann, B. (1998) Target-cell-specific facilitation and depression in neocortical circuits. Nat. Neurosci. 1, 279-285.

Rockland, K. S., and Knutson, T. (2000) Feedback connections from area MT of the squirrel monkey to areas V1 and V2. J. Comp. Neurol. 425, 345-368.

Rockland, K. S., Andresen, J., Cowie, R. J., and Robinson, D. L. (1999) Single axon analysis of pulvinocortical connections to several visual areas in the macaque. $J$. Comp. Neurol. 406, 221-250.

Rozov, A., Jerecic, J., Sakmann, B., and Burnashev, N. (2001) AMPA receptor channels with long-lasting desensitization in bipolar interneurons contribute to synaptic depression in a novel feedback circuit in layer $2 / 3$ of rat neocortex. J. Neurosci. 21 8062-8071.

Saggau, P. (2006) New methods and uses for fast optical scanning. Current Opinion in Neurobiology 16, 543-550.

Schubert, D., Staiger, J. F., Cho, N., Kotter, R., Zilles, K., and Luhmann, H. J. (2001) Layer-specific intracolumnar and transcolumnar functional connectivity of layer $\mathrm{V}$ pyramidal cells in rat barrel cortex. J. Neurosci. 21, 3580-3592.
Schubert D, Kotter R, Staiger JF. (2007) Mapping functional connectivity in barrel-related columns reveals layer- and cell type-specific microcircuits. Brain Struct Funct. 212(2):107-19.

Silberberg, G., and Markram, H. (2007) Disynaptic inhibition between neocortical pyramidal cells mediated by Martinotti cells. Neuron. 53, 735-746.

Simon, A., Olah, S., Molnar, G., Szabadics, J., and Tamas, G. (2005) Gap-junctional coupling between neurogliaform cells and various interneuron types in the neocortex. J. Neurosci. 25, 6278-6285.

Somogyi, P. (1977) A specific 'axo-axonal' interneuron in the visual cortex of the rat. Brain Res. 136, 345-350.

Somogyi, P., and Cowey, A. (1984) Double bouquet cells. In: Cerebral cortex, Vol. 1 A. Peters, E. G. Jones, (eds.), New York: Plenum, pp. 337-360.

Somogyi, P., and Klausberger, T. (2005) Defined types of cortical interneurone structure space and spike timing in the hippocampus. J. Physiol. 562, 9-26.

Song S, Sjostrom PJ, Reigl M, Nelson S, Chklovskii DB. (2005) Highly nonrandom features of synaptic connectivity in local cortical circuits. PLoS Biol. 3(3):e68.

Spatz, W. B., Tigges, J., and Tigges, M. (1970) Subcortical projections, cortical associations and some intrinsic interlaminar connections of the striate cortex in the squirre monkey. (Saimiri). J. Comp. Neurol. 140, 155-174.

Staiger, J. F., Zilles, K., and Freund, T. F. (1996) Recurrent axon collaterals of corticothalamic projection neurons in rat primary somatosensory cortex contribute to excitatory and inhibitory feedback loops. Anat. Embryol. (Berl) 194, 533-543.

Staiger, J. F., Zilles, K., and Freund, T. F. (1996) Distribution of GABAergic elements postsynaptic to ventroposteromedial thalamic projections in layer IV of rat barrel cortex. Eur. J. Neurosci. 8, 2273-2285.

Staiger, J. F., Freund, T. F., and Zilles, K. (1997) Interneurons immunoreactive for vasoactive intestinal polypeptide (VIP) are extensively innervated by parvalbumin-containing boutons in rat primary somatosensory cortex. Eur. J. Neurosci. 9, 2259-2268.

Szabadics, J., Varga, C., Molnar, G., Olah, S., Barzo, P., and Tamás, G. (2006) Excitatory effect of GABAergic axo-axonic cells in cortical microcircuits. Science. 311, 233-235.

Tamás, G., and Szabadics, J. (2004) Summation of unitary IPSPs Elicited by identified axo-axonic interneurons Cereb. Cortex 14, 823-826.

Tamas, G., Buhl, E. H., and Somogyi, P. (1997) Fast IPSPs elicited via multiple synaptic release sites by different types of GABAergic neurone in the cat visual cortex. $J$. Physiol. 500, 715-738.

Tamas, G., Somogyi, P., and Buhl, E. H (1998) Differentially interconnected networks of GABAergic interneurons in the visual cortex of the cat. J. Neurosci. 18, 4255-4270.

Tamás, G., Lorincz, A., Simon, A., and Szabadics, J. (2003) Identified sources and targets of slow inhibition in the neocortex. Science 299, 1902-1905.

Tarczy-Hornoch, K., Martin, K. A., Jack, J. J., and Stratford, K. J. (1998) Synaptic interactions between smooth and spiny neurones in layer 4 of cat visual cortex in vitro. J. Physiol. 508, 351-363.

Tarczy-Hornoch, K., Martin, K. A., Stratford, K. J., and Jack, J. J. (1999) Intracortical excitation of spiny neurons in layer 4 of cat striate cortex in vitro. Cereb. Cortex. 9 , 833-843.

Thomson, A. M. (1997) Activity-dependent properties of synaptic transmission at two classes of connections made by rat neocortical pyramidal axons in vitro. J. Physiol. $502,131-147$.

Thomson, A. M. (2000) Molecular frequency filters at central synapses. Prog. Neurobiol. 62, 159-196.

Thomson, A. M., and Bannister, A. P. (1998) Postsynaptic pyramidal target selection by descending layer III pyramidal axons: dual intracellular recordings and biocytin filling in slices of rat neocortex. Neuroscience 84, 669-683.

Thomson, A. M., and Destexhe, A. (1999) Dual intracellular recordings and computational models of slow IPSPs in rat neocortical and hippocampal slices. Neuroscience 92 , 1193-1215.

Thomson, A. M., and West, DC. (1993) Fluctuations in pyramid-pyramid EPSPs modified by presynaptic firing pattern and postsynaptic membrane potential using paired intracellular recordings in rat neocortex. Neuroscience 54, 329-346.

Thomson, A. M., and West, D. C. (2003) Presynaptic frequency filtering in the gamma frequency band; dual intracellular recordings in slices of adult rat and cat neocortex. Cereb. Cortex 13, 136-143.

Thomson, A. M., Deuchars, J., and West, D. C. (1993) Large, deep layer pyramidpyramid single axon EPSPs in slices of rat motor cortex display paired pulse and frequency-dependent depression, mediated presynaptically and self-facilitation, mediated postsynaptically. J. Neurophysiol. 70, 2354-2369.

Thomson, A. M., West, D. C., and Deuchars, J. (1995) Properties of single axon excitatory postsynaptic potentials elicited in spiny interneurons by action potentials in pyramidal neurons in slices of rat neocortex. Neuroscience 69, 727-738.

Thomson, A. M., West, D. C., Hahn, J., and Deuchars, J. (1996) Single axon IPSPs elicited in pyramidal cells by three classes of interneurones in slices of rat neocortex. J. Physiol. 496, 81-102.

Thomson, A. M., West, D. C., Wang, Y., and Bannister, A. P. (2002) Synaptic connections and small circuits involving excitatory and inhibitory neurons in layers $2-5$ of adult rat and cat neocortex: triple intracellular recordings and biocytin labeling in vitro. Cereb. Cortex. 12, 936-953.

Toledo-Rodriguez, M., Goodman, P., Illic, M., Wu, C., and Markram, H. (2005) Neuropeptide and calcium-binding protein gene expression profiles predict neuronal anatomical type in the juvenile rat. J. Physiol. 567, 401-413.

Uematsu, M., Hirai, Y., Karube, F., Ebihara, S., Kato, M., Abe, K., Obata, K., Yoshida, S., Hirabayashi, M., Yanagawa, Y., and Kawaguchi, Y. (2007) Quantitative chemical composition of cortical GABAergic neurons revealed in transgenic venus-expressing rats. Cereb Cortex. May 20; [Epub ahead of print]. 
Valverde, F. (1976) Aspects of cortical organization related to the geometry of neurons with intra-cortical axons. J. Neurocytol. 5, 509-529.

Van Horn, S. C., and Sherman, S. M. (2004) Differences in projection patterns between large and small corticothalamic terminals. J. Comp. Neurol. 475, 406-415.

von Engelhardt, J., Eliava, M., Meyer, A. H., Rozov, A., and Monyer, H. (2007) Functional characterization of intrinsic cholinergic interneurons in the cortex. J. Neurosci. 27 5633-5642.

Wang, Y., Gupta, A., Toledo-Rodriguez, M., Wu C. Z., and Markram, H. (2002) Anatomical, physiological, molecular and circuit properties of nest basket cells in the developing somatosensory cortex. Cereb. Cortex 12, 395-410.

Wang, Y., Toledo-Rodriguez, M., Gupta, A., Wu, C., Silberberg, G., Luo, J., and Markram H. (2004) Anatomical, physiological and molecular properties of Martinotti cells in the somatosensory cortex of the juvenile rat. J. Physiol. 561, 65-90.

Wang, Y., Markram, H., Goodman, P. H., Berger, T. K., Ma, J., and Goldman-Rakic P. S. (2006) Heterogeneity in the pyramidal network of the medial prefrontal cortex. Nat Neurosci. 9, 534-542.

Wang, H., Peca, J., Matsuzaki, M., Matsuzaki, K., Noguchi, J., Qiu, L., Wang, D., Zhang, F., Boyden, E., Deisseroth, K., Kasai, H., Hall, W. C., Feng, G., and Augustine, G. J. (2007) High-speed mapping of synaptic connectivity using photostimulation in Channelrhodopsin-2 transgenic mice. Proc. Natl. Acad. Sci. USA 104 8143-8148.

West, D. C., Mercer, A., Kirchhecker, S., Morris, O. T., and Thomson, A. M. (2006) Layer 6 cortico-thalamic pyramidal cells preferentially innervate interneurons and generate facilitating EPSPs. Cereb. Cortex. 16, 200-211.

White, E. L., and Czeiger, D. (1991) Synapses made by axons of callosal projection neurons in mouse somatosensory cortex: emphasis on intrinsic connections. J. Comp. Neurol. 303, 233-244.

White, E. L., and Hersch, S. M. (1981) Thalamocortical synapses of pyramidal cells which project from Sml to Msl cortex in the mouse. J. Comp. Neurol. 198, 167-181.

White, E. L., and Hersch, S. M. (1982) A quantitative study of thalamocortical and other synapses involving the apical dendrites of corticothalamic projection cells in mouse Sml cortex. J. Neurocytol. 11, 137-157.

White, E. L., and Keller, A. (1987) Intrinsic circuitry involving the local axon collaterals of corticothalamic projection cells in mouse Sml cortex. J. Comp. Neurol. 262, 13-26.

Whittington, M. A., Faulkner, H. J., Doheny, H. C., and Traub, R. D. (2000) Neuronal fast oscillations as a target site for psychoactive drugs. Pharmacol. Ther. 86, 171-190.
Wickersham, I. R., Lyon, D. C., Barnard, R. J., Mori, T., Finke, S., Conzelmann, K. K., Young, J. A., and Callaway, E. M. (2007) Monosynaptic restriction of transsynaptic tracing from single, genetically targeted neurons. Neuron.53, 639647.

Wiser, A. K., and Callaway, E. M. (1996) Contributions of individual layer 6 pyramidal neurons to local circuitry in the macaque primary visual cortex. J. Neurosci. 16 2724-2739.

Yasuda, R. (2006) Imaging spatiotemporal dynamics of neuronal signaling using fluorescence resonance energy transfer and fluorescence lifetime imaging microscopy. Curr. Opini. Neurobiol. 16, 551-561.

Yasuda, R., Harvey, C., Zhong, H., Sobczyk, A., and Svoboda, K (2006) Super-sensitive Ras activation in dendrites and spines revealed by 2-photon fluorescence lifetime imaging, Nat. Neurosci. 9, 283-289.

Yoshimura, Y., and Callaway, E. M. (2005) Fine-scale specificity of cortical networks depends on inhibitory cell type and connectivity. Nat. Neurosci. 8, 15521559.

Yoshimura, Y., Dantzker, J. L., and Callaway, E. M. (2005) Excitatory cortical neurons form fine-scale functional networks. Nature 433, 868-873.

Yoshioka, T., Levitt, J. B., and Lund, J. S. (1994) Independence and merger of thalamocortical channels within macaque monkey primary visual cortex: anatomy of interlaminar projections. Vis. Neurosci. 11, 1-23.

Yuste, R. (2005) Fluorescence microscopy today. Nat. Methods. 2, 902-904.

Zhang, Z. W., and Deschenes, M. (1998) Projections to layer VI of the posteromedial barrel field in the rat: a reappraisal of the role of corticothalamic pathways. Cereb. Cortex. 8, 428-436.

Zhang, F., Wang, L. P., Boyden, E. S., and Deisseroth, K. (2006) Channelrhodopsin-2 and optical control of excitable cells. Nat. Methods. 3, 785-792.

Zhang, F., Wang, L. P., Brauner, M., Liewald, J. F., Kay, K., Watzke, N., Wood, P. G., Bamberg, E., Nagel, G., Gottschalk, A., and Deisseroth, K. (2007) Multimodal fast optical interrogation of neural circuitry. Nature 446, 633-639.

Zhu, Y., Stornetta, R. L., and Zhu, J. J. (2004) Chandelier cells control excessive cortical excitation: characteristics of whisker-evoked synaptic responses of layer $2 / 3$ nonpyramidal and pyramidal neurons. J. Neurosci. 24, 5101-5108.

doi: 10.3389/neuro.01/1.1.002.2007 